\title{
A Numerical Study for Flow Excitation and Performance of Rampressor Inlet considering Rotor Motion
}

\author{
Weijia Kang, Zhansheng Liu, Jiangbo Lu, Yu Wang, and Yanyang Dong \\ School of Energy Science and Engineering, Harbin Institute of Technology, Harbin, Heilongjiang 150001, China \\ Correspondence should be addressed to Weijia Kang; kwj1221@163.com
}

Received 21 February 2014; Revised 1 July 2014; Accepted 2 July 2014; Published 24 July 2014

Academic Editor: Longjun Dong

Copyright ( 2014 Weijia Kang et al. This is an open access article distributed under the Creative Commons Attribution License, which permits unrestricted use, distribution, and reproduction in any medium, provided the original work is properly cited.

\begin{abstract}
A unique supersonic compressor rotor with high pressure ratio, termed the Rampressor, is presented by Ramgen Power Systems, Inc. (RPS). In order to obtain the excitation characteristic and performance of Rampressor inlet flow field under external excitation, compression inlet flow of Rampressor is studied with considering Rampressor rotor whirling. Flow excitation characteristics and performance of Rampressor inlet are analyzed under different frequency and amplitude of Rampressor rotor whirling. The results indicate that the rotor whirling has a significant effect for flow excitation characteristics and performance of Rampressor inlet. The effect of rotor whirling on the different inlet location excitation has a definite phase difference. Inlet excitation becomes more complex along with the inlet flow path. More frequency components appear in the excitation spectrum of Rampressor inlet with considering Rampressor rotor whirling. The main frequency component is the fundamental frequency, which is caused by the rotor whirling. Besides the fundamental frequency, the double frequency components are generated due to the coupling between inlet compression flow of Rampressor rotor and rotor whirling, especially in the subsonic diffuser of Rampressor rotor inlet. With the increment of rotor whirling frequency and whirling amplitude, the complexity of Rampressor inlet excitation increases, and the stability of Rampressor inlet performance deteriorates.
\end{abstract}

\section{Introduction}

Ramgen engine with a proof-of-concept version of a new type of compression system has been proposed by American Ramgen Power Systems, Inc. [1, 2]. The core part of Ramgen engine is Rampressor. Rampressor inlet is formed of the rotor compression ramp and engine casing. Shock wave compression system is employed in the Rampressor inlet. Compared with traditional axial or centrifugal compressor, Ramgen engine has some distinct technical characteristics [3-5] such as a higher stage pressure ratio, greater compression efficiency, higher operational reliability, and smaller volume and compact structure.

Ramgen Power Systems, Inc. has developed the related numerical simulation of Rampressor inlet, which provided the advantageous validation for the design of inlet flow-path structure and supersonic shock wave compression system [6]. A two-dimensional model of Rampressor rotor inlet was designed and established by Han et al. [7], and this model was numerically studied by CFD. The effects of rotational speed of
Rampressor rotor and exit back pressure on the shock wave structure, flow field distributions, and flow performance of the two-dimensional inlet model were given in their research. Based on the previous research of two-dimensional model of Rampressor inlet, a three-dimensional model of Rampressor rotor inlet was also designed and numerically studied by Han et al. [8]. Yang et al. [9] also numerically analyzed the flow field of Rampressor inlet in different geometrical parameters such as strake section shape, throat length-height ratio, strake stagger angle, compression ramp angle, subsonic divergent angle, and throat contraction ratio. The effects of these geometrical parameters on the flow field distributions and the flow performance of Rampressor inlet have been given to provide the foundation for the subsequent optimization of inlet structure and performance. In order to promote the whole performance of Rampressor inlet, the research of flow control technology and the tip clearance control technology has also been presented and tested by Ramgen Power Systems, Inc. Basing on these design techniques, an industrial $\mathrm{CO}_{2}$ compressor has been proposed and implemented, which offers 


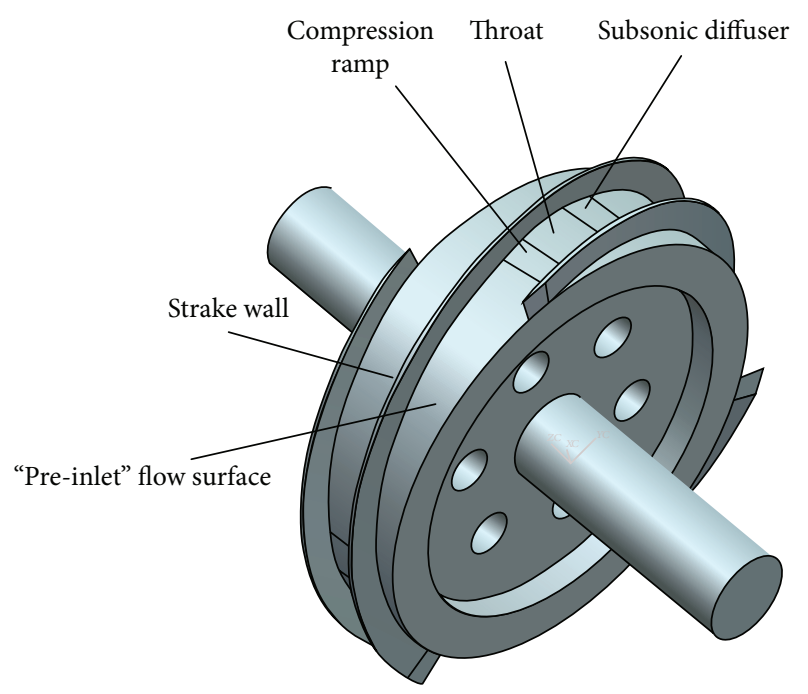

FIGURE 1: Model of Rampressor rotor.

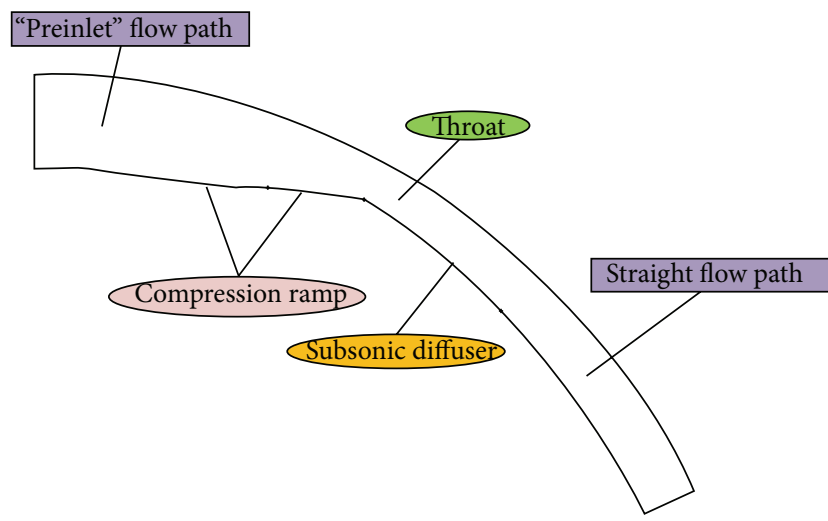

FIgURE 2: Two-dimensional simplified model of Rampressor inlet.

significant cost savings and efficiency advantages over other typical $\mathrm{CO}_{2}$ compressor systems used for industrial applications, and its highest pressure ratio can achieve $200: 1$ [10]. At present, a 13,000 horsepower carbon dioxide Rampressor was constructed and tested in New York, and significant progress had been achieved in the design and test of the advanced vortex combustor (AVC) system until the spring of 2011 [11].

Operational condition of Rampressor rotor is determined by the inlet excitation characteristic that causes the rotor whirl, simultaneously inlet flow distribution and excitation characteristic are affected by rotor whirl. However, most of the previous researches emphasized on Rampressor inlet structural design based on aerodynamic performance, and Rampressor inlet excitation characteristics had not been reported in the references. Therefore, it is necessary to study the effect of rotor whirl on flow excitation characteristics and performance of Rampressor inlet.

Models of Rampressor rotor and inlet are established in this study, and the effects of exit back pressure on the shock wave structure, flow field distribution, and flow performance of Rampressor inlet are numerically studied. Then this paper emphatically analyzes the inlet flow field considering

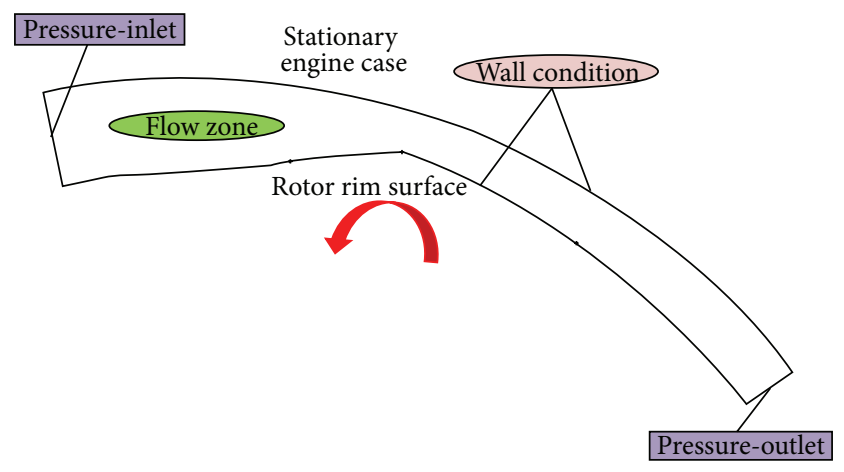

FIGURE 3: Specific boundary conditions of Rampressor inlet.

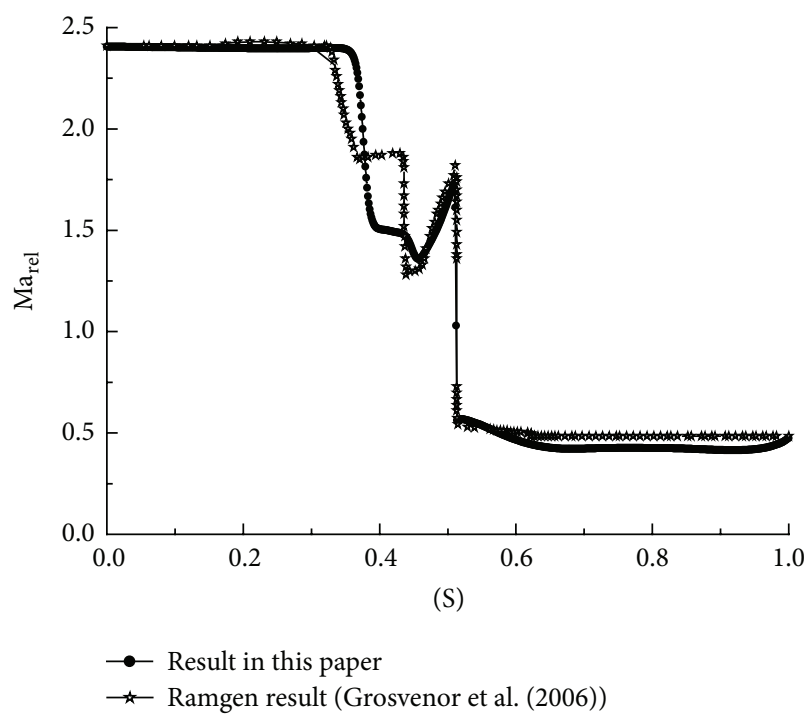

FIGURE 4: Comparison of relative centerline Mach number versus normalized streamwise distance (S) between result in this paper and result in Ramgen.

Rampressor rotor whirling. The variations of inlet excitation characteristic and performance under rotor whirling are obtained and discussed in this paper.

\section{Numerical Modeling}

The Rampressor rotor impeller can be developed with two, three, four, or more inlets according to the Rampressor flow. The Rampressor rotor model in this study is established with three inlet flow paths as shown in Figure 1. The supersonic rotor flow path is formed by three strakes mounted on the rim of the rotor. These strakes are mounted on the rotor at a shallow angle, typically $8^{\circ}$, and formed the axial boundaries of each of the three flow paths. Figure 1 shows that each flow path includes "preinlet" surface, compression ramp, throat, and subsonic diffuser. The principal shock system is generated by the compression ramp integrated into the rim of the rotor. The compression ramp is designed to create a series of oblique shock waves. 


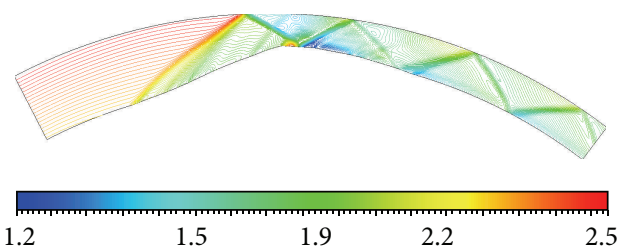

(a) Gird size $=11,636$

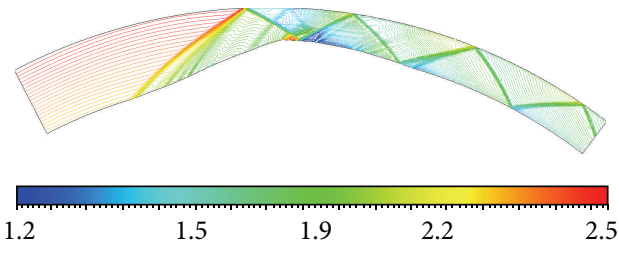

(c) Gird size $=45,439$

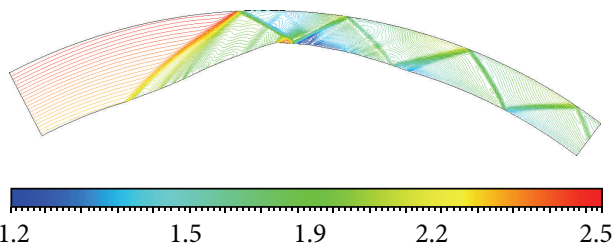

(b) Gird size $=20,249$

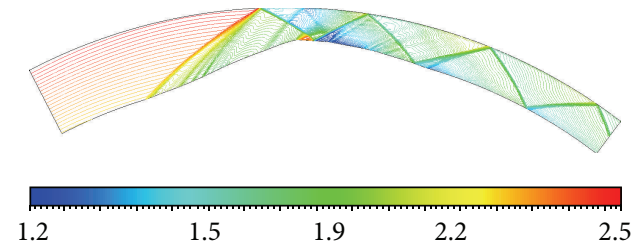

(d) Gird size $=84,590$

FIGURE 5: Comparison of Mach number contour of Rampressor inlet in different grid sizes.

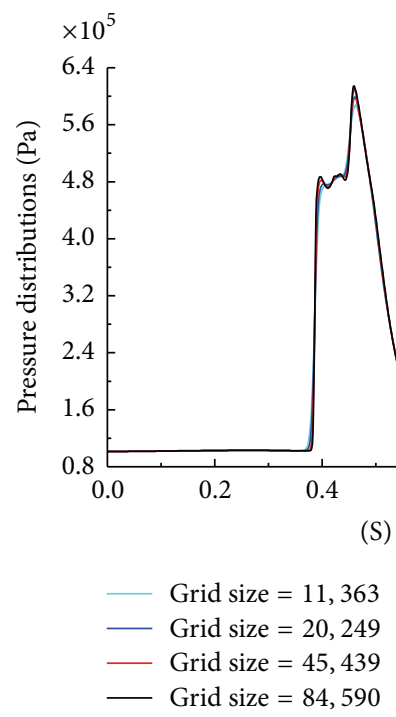

FIGURE 6: Comparison of pressure distribution of stationary engine case versus normalized streamwise distance in different grid sizes.

The three inlets of the designed Rampressor are the symmetric periodic layout on the rotor. If Rampressor rotor does not whirl, the flows of the three inlets are of central symmetry, so one of the three inlets can be used for numerical study of the flow field. Beside this, the rotor whirl is generally generated in the radial direction, but the difference between three-dimensional and two-dimensional models is in the axial direction. Because the rotor whirling almost has no effect on the axial structure of three-dimensional model, the axial flow gradient of the inlet can be ignored. Therefore, it is accepted to use the two-dimensional model for studying the excitation characteristic and performance of Rampressor inlet with considering Rampressor rotor whirling.

The two-dimensional simplified model of Rampressor inlet is established for numerical study of flow excitation and performance as shown in Figure 2. It consists of "preinlet"

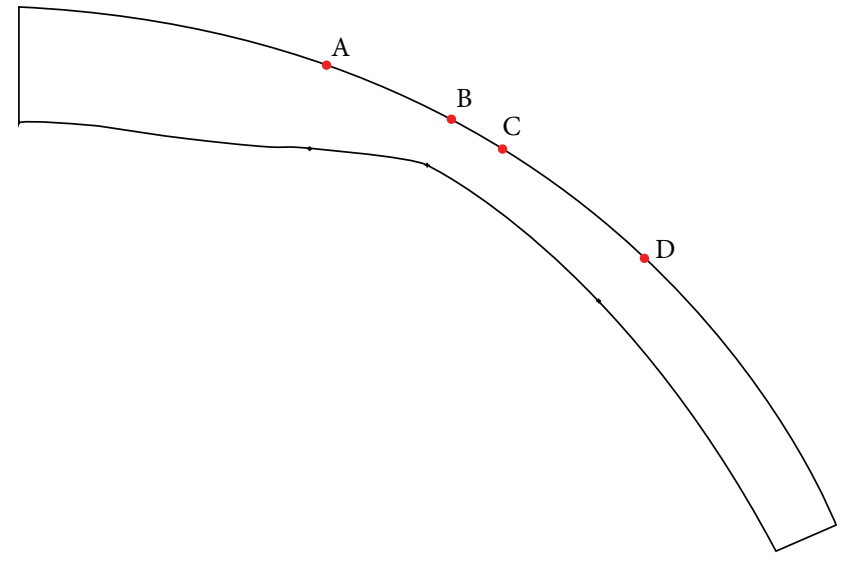

FIGURE 7: Schematic diagram of key point in Rampressor inlet.

flow path, compression ramp, throat, subsonic diffuser, and straight flow path.

Solution of the compressible form of the Euler equations for the simulations presented herein is conducted using a finite-volume and density based scheme in the fluent simulation of this study. So the two-dimensional simplified model does not take into account the boundary layer developed upward, but the centrifugal force is taken into consideration in the calculation. The calculation formulation is implicit, and the convection flux type is Roe averaged flux difference splitting (Roe-FDS). Figure 3 shows boundary conditions of Rampressor rotor inlet. The exact boundary conditions are as follows.

(a) Inflow boundary condition: the Mach number is 0.348 , the total pressure is $P_{t}=1.08676 \times 10^{5} \mathrm{~Pa}$, the static pressure is $P_{0}=1.01325 \times 10^{5} \mathrm{~Pa}$, and the total temperature is $T_{t}=306 \mathrm{~K}$.

(b) Wall boundary condition: the no-slip and adiabatic wall boundary conditions are placed on the wall surfaces. The engine case is the stationary adiabatic wall. The rotor rim is also adiabatic wall, and the 


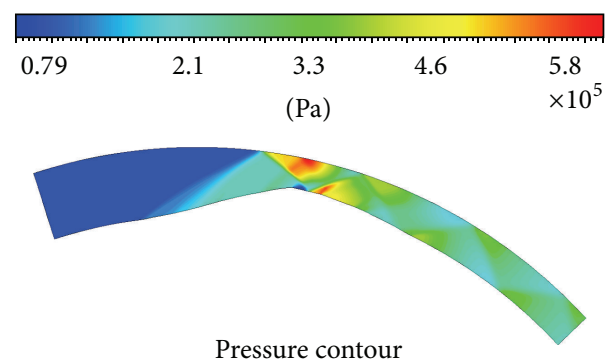

Pressure contour

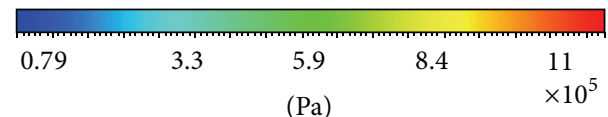

(Pa)

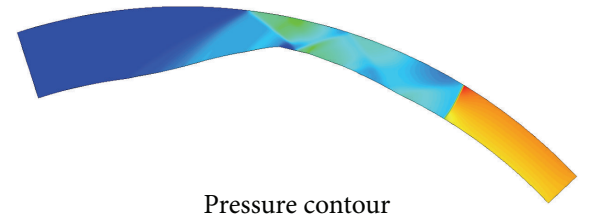

Pressure contour

(b) $P_{r}=9.0$

a) $P_{r}=8.0$
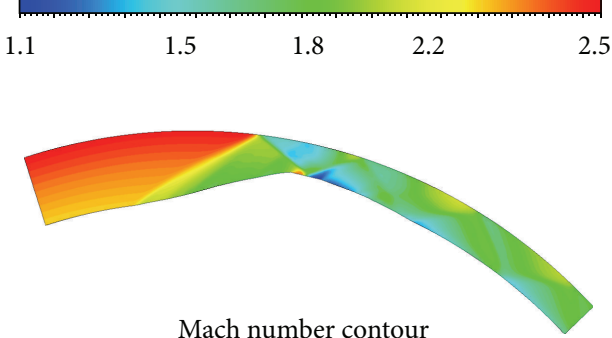

Mach number contour
0.35

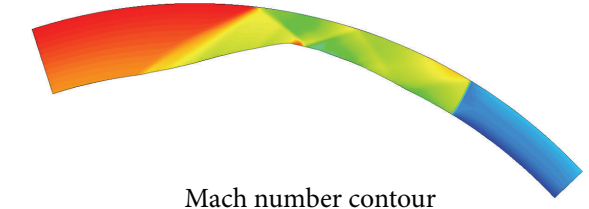

Mach number contour

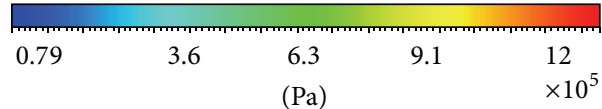

0.13

\begin{tabular}{lllll}
\hline 13 & 0.72 & 1.3 & 1.9 & 2.5
\end{tabular}
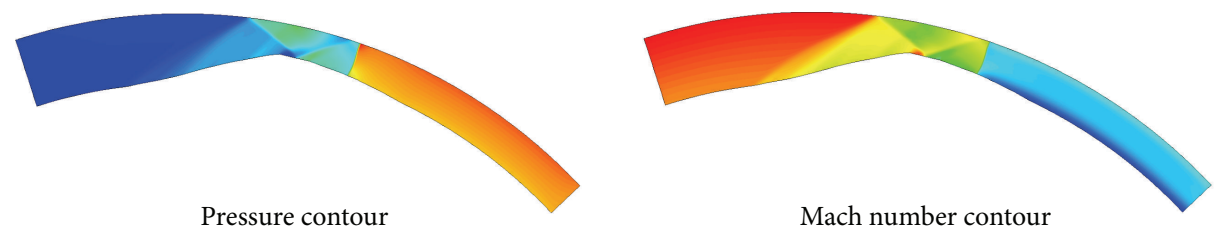

(c) $P_{r}=10.0$

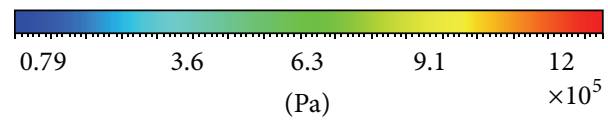

0.13

Mach number contour
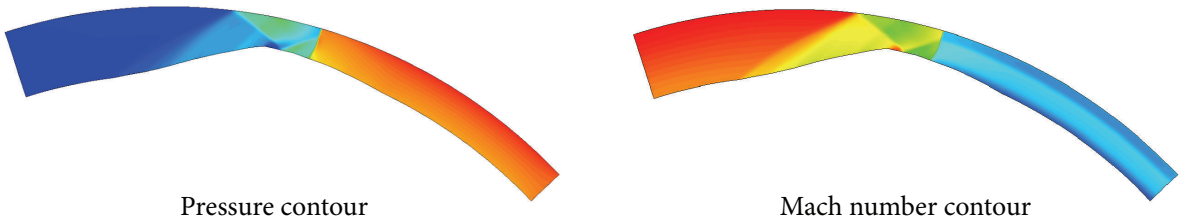

(d) $P_{r}=10.6$

FIgure 8: Flow distribution of Rampressor inlet in different $P_{r}$.

direction of rotation of the rim shown in Figure 3 is right to left. In the present case proposed in this paper, the designed Rampressor rotor speed is 40,600 rpm.

(c) Subsonic outlet boundary condition: the exit condition is set to the pressure outlet in order to generate normal shock waves within internal inlet flow field.

\section{Validation of Numerical Method}

The numerical method of this paper is validated by comparing the numerical results of Rampressor inlet flow field of
American Ramgen Power Systems, Inc. [6], which is based on the same calculation parameters such as the initial conditions, the boundary conditions, and the Rampressor rotor speed. The variation of relative centerline Mach number versus normalized streamwise distance $(S)$ in the numerical study shows a good agreement with the Ramgen results (as shown in Figure 4). The numerical method proposed in this paper is feasible to solve supersonic compressible flow of Rampressor inlet.

In this paper, high quality grid of two-dimensional simplified model of Rampressor inlet is calculated by using 


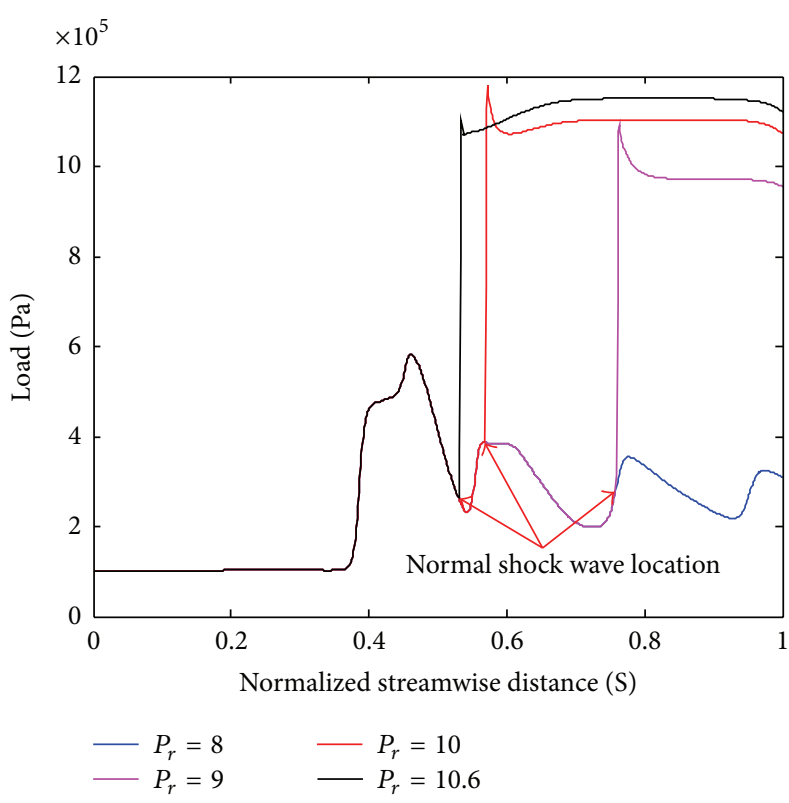

(a) Stationary engine case

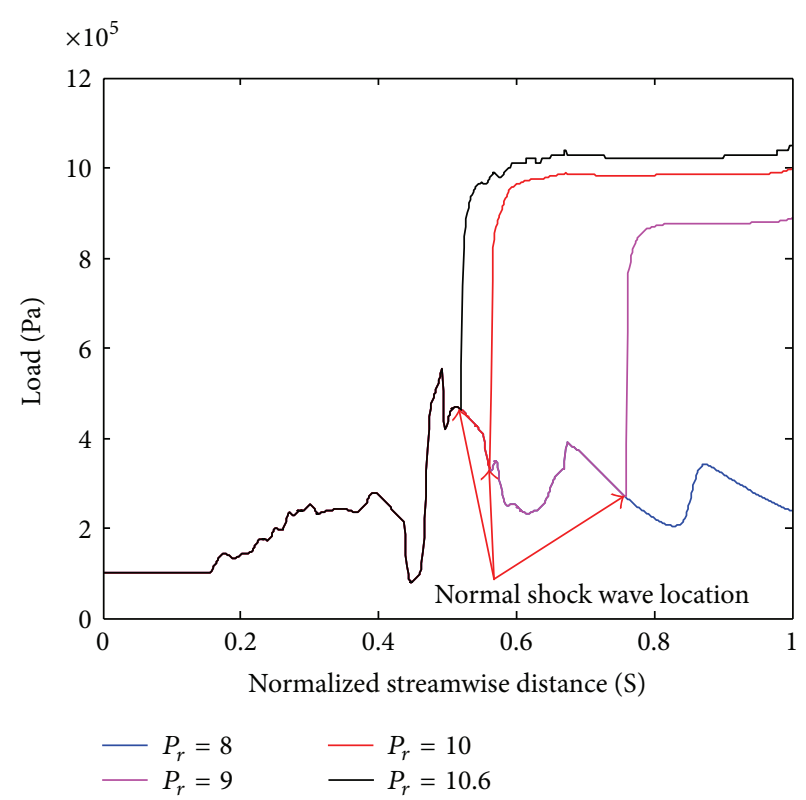

(b) Rotor rim surface

FIgURE 9: Pressure distribution of Rampressor inlet in different $P_{r}$.

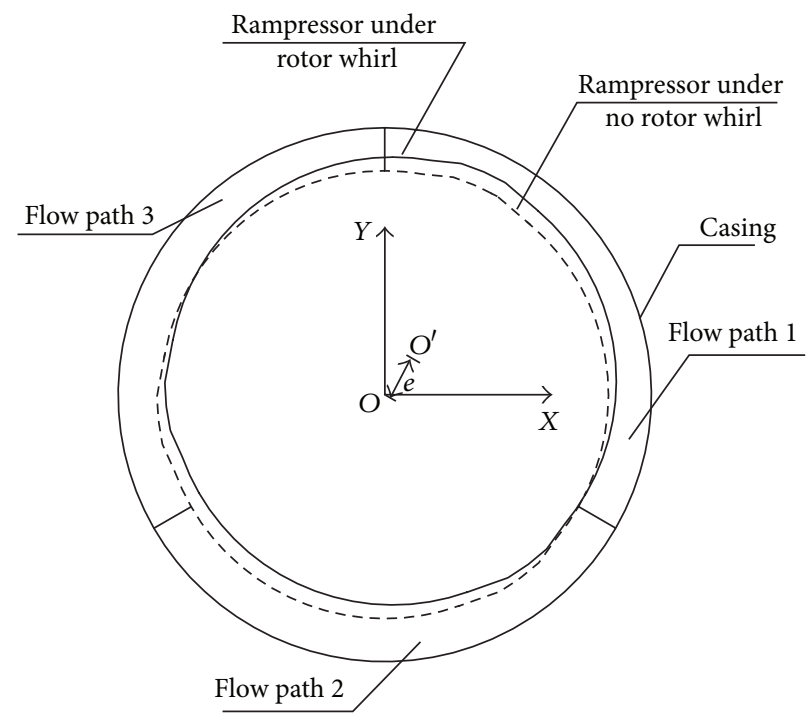

Figure 10: Structure schematic diagram of inlet flow path on Rampressor rotor.

the structured grid technology. The computational grid density of Rampressor inlet model should be examined. Mach number distributions of Rampressor inlet are computed in different grid sizes. Comparison of Mach number contour of Rampressor inlet in different grid sizes is given in Figure 5. The grid density has some influence on the flow field, but the distribution of the shock waves is essentially similar. With the increment of grid size, the Mach number contours of Rampressor inlet gradually tend to be same. The Mach number distribution of the grid size 45,439 is basically identical to that of the grid size 84,590 . Therefore, flow field distribution of Rampressor inlet can be calculated accurately by the computational gird sizes 45,439 and 84,590 .

Figure 6 shows comparison of pressure distribution of the stationary engine case versus normalized streamwise distance in different grid sizes. The grid density also has a few effects on the pressure distribution along the stationary engine case, but the location of the shock waves and the pressure fluctuation are basically identical. With the increment of grid size, the pressure distributions of stationary engine case gradually have a tendency to coincide. The pressure distribution of the stationary engine case in the numerical simulation of the grid 

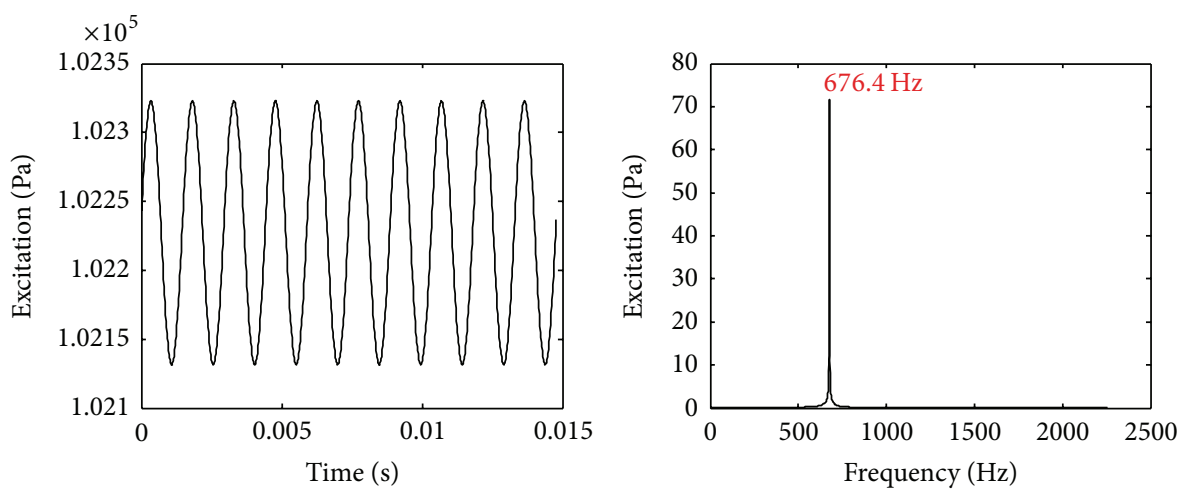

(a) Point $\mathrm{A}$
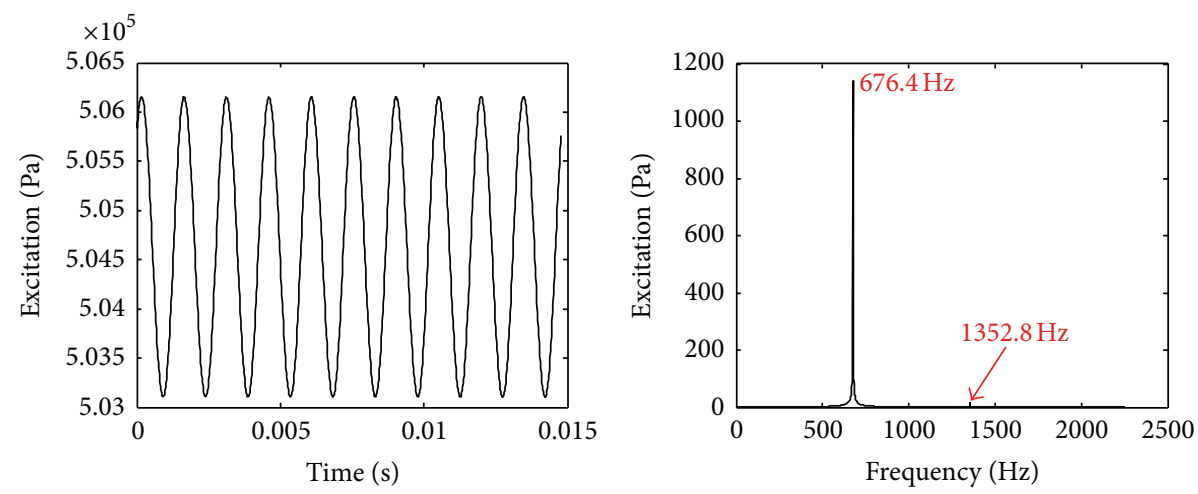

(b) Point B
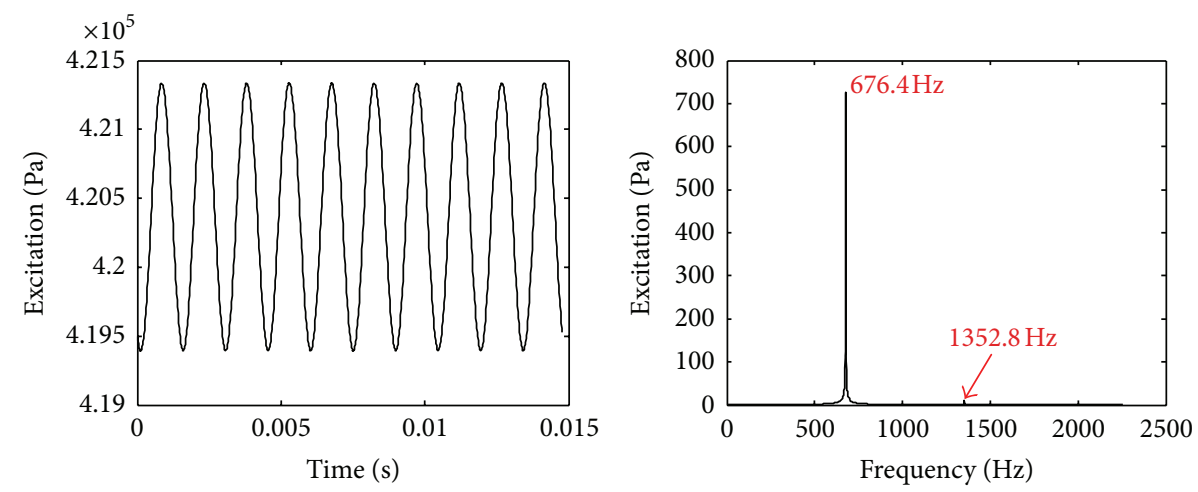

(c) Point C
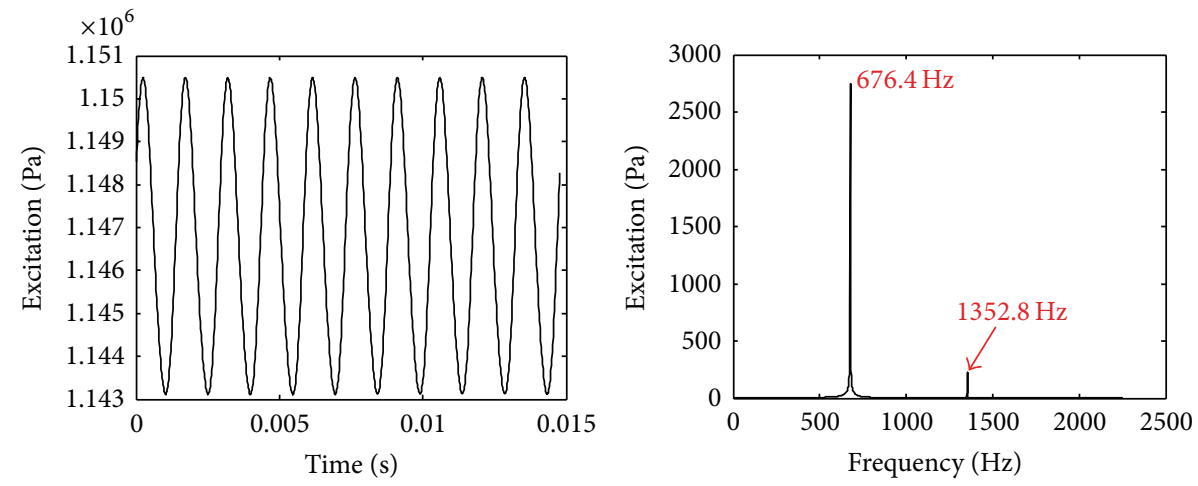

(d) Point D

FIGURE 11: Pressure pulsation time history and spectrogram on every key point of Rampressor rotor inlet. 


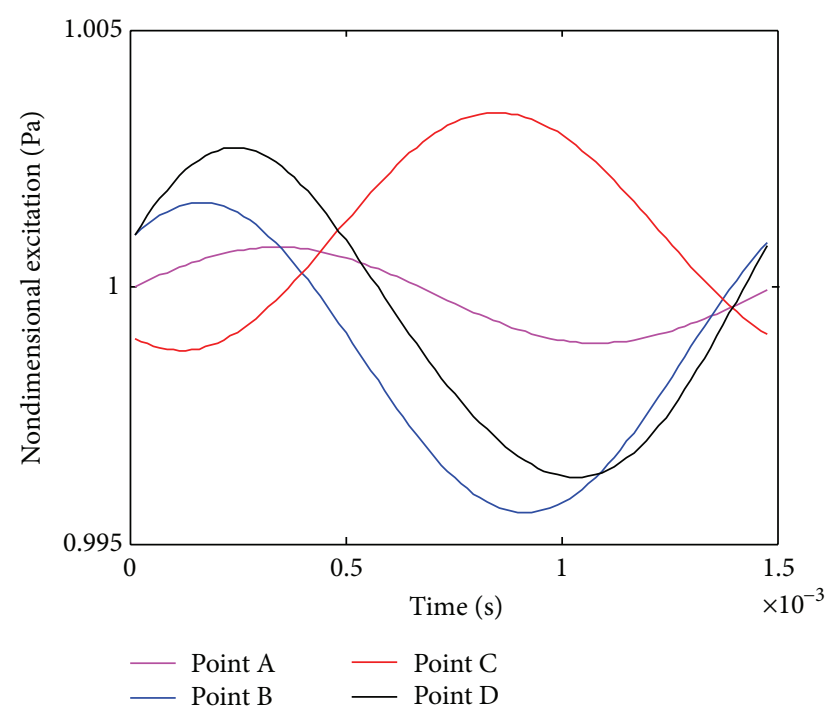

FIgURE 12: Time history of nondimensional excitation.

size 45,439 shows a good agreement with that of the grid size 84,590 (Figure 6).

The computational model of grid size 45,439 is chosen for the latter Rampressor inlet simulation in comprehensive consideration with computational accuracy and computational complexity. The grid employed 781 nodes (maximum number) in the streamwise direction and 88 (maximum number) in the radial.

\section{Simulation Results and Analysis}

The following parameters are defined to analyze the performances of Rampressor inlet flow path for different operating conditions $[4,7]$. follows.

Static pressure ratio of flow path can be obtained as

$$
p_{s}=\frac{p_{\text {outlet }}}{p_{\text {inlet }}}
$$

where $p_{\text {outlet }}$ and $p_{\text {inlet }}$ are the static pressure of entrance and exit of flow path, respectively.

Total-pressure recovery coefficient of flow path:

$$
p_{R}=\frac{p_{\text {outlet }}^{*}}{p_{\text {inlet }}^{*}}
$$

where $p_{\text {outlet }}^{*}$ and $p_{\text {inlet }}^{*}$ are the total pressure of entrance and exit of flow path, respectively.

Pressurization ratio in flow path:

$$
p_{z}=\frac{p_{\text {outlet }}^{*}}{p_{\text {inlet }}}=p_{R}\left(1+\frac{\kappa-1}{2} \mathrm{Ma}_{\text {inlet }}^{2}\right)^{\kappa /(\kappa-1)} .
$$

Loss coefficient in flow path:

$$
\bar{\omega}=\frac{1-p_{R}}{1-p_{s}\left(\mathrm{Ma}_{\text {inlet }}\right)},
$$

where $p_{R}$ is total-pressure recovery coefficient, $p_{s}$ is static pressure ratio, and $\mathrm{Ma}_{\text {inlet }}$ is airflow Mach number.

Kinetic energy efficiency in flow path:

$$
\eta=1-\frac{2}{(\kappa-1) \mathrm{Ma}_{\text {inlet }}^{2}}\left[\left(\frac{1}{p_{R}}\right)^{(\kappa-1) / \kappa}-1\right],
$$

where $\kappa$ is adiabatic exponent.

Nondimensional total pressure distortion of flow-path exit is defined as

$$
\Delta=\frac{P_{t, \mathrm{MAX}}-P_{t, \mathrm{MIN}}}{P_{t, \mathrm{avg}}},
$$

where $P_{t, \mathrm{MAX}}$ and $P_{t, \mathrm{MIN}}$ are maximum total-pressure and minimum total-pressure of flow-path exit, respectively, and $P_{t, \text { avg }}$ is average total pressure of flow-path exit.

In order to study the excitation characteristic of Rampressor inlet well, pressure pulsation of key points in Rampressor inlet should be measured. The arrangement of key points is shown in Figure 7. The points A, B, C, and D are located in the middle part of the compression ramp, the entrance of the throat, entrance of subsonic diffuser, and the entrance of straight flow path, respectively.

4.1. Performance and Excitation Characteristic of Inlet under no Rotor Whirling. The equation $P_{r}=P_{b} / P_{0}$ is defined, where $P_{b}$ is the exit back pressure of Rampressor inlet, so $P_{r}$ is the nondimensional back pressure. Figure 8 shows the static pressure contour and the Mach number contour of twodimensional inlet in different $P_{r}=8.0,9.0,10.0$, and 10.60 when the design rotor speed is $40,600 \mathrm{rpm}$.

A series of oblique shock waves is generated by the compression ramp of inlet flow path to achieve airflow compression, and the airflow pressure after the shock wave increases abruptly as shown in Figure 8. Several reflections of the oblique shock waves are produced between the stationary engine case and the Rampressor rotor rim surface, followed by a terminal normal shock. The Mach number contours show that the airflow speed after a normal shock wave reduces to be subsonic. When $P_{r}$ increases from 9 to 10.6 , the position where the normal shock wave appears gradually moves towards the inlet throat. The position of the normal shock wave just locates in the throat when $P_{r}$ equals 10.60, and Rampressor inlet reaches the critical state.

Pressure distributions along stationary engine case and rotor rim surface of Rampressor inlet are given in Figure 9.

The pressure distribution curves of the stationary engine case and rotor rim surface are completely overlapped before normal shock wave in the different $P_{r}$ as shown in Figure 9. Therefore, aerodynamic loading of inlet supersonic compression section is accordant in the different $P_{r}$ and is not affected by the exit condition (combustor). Figure 9 illustrates that the loading of the stationary engine case and rotor rim surface after normal shock wave suddenly rises and then tends to be a certain value along inlet flow path. The results indicate that along with the increment of $P_{r}$, the position of the normal shock wave gradually moves forward, and then aerodynamic loading of the stationary engine case and rotor rim surface also increases. 


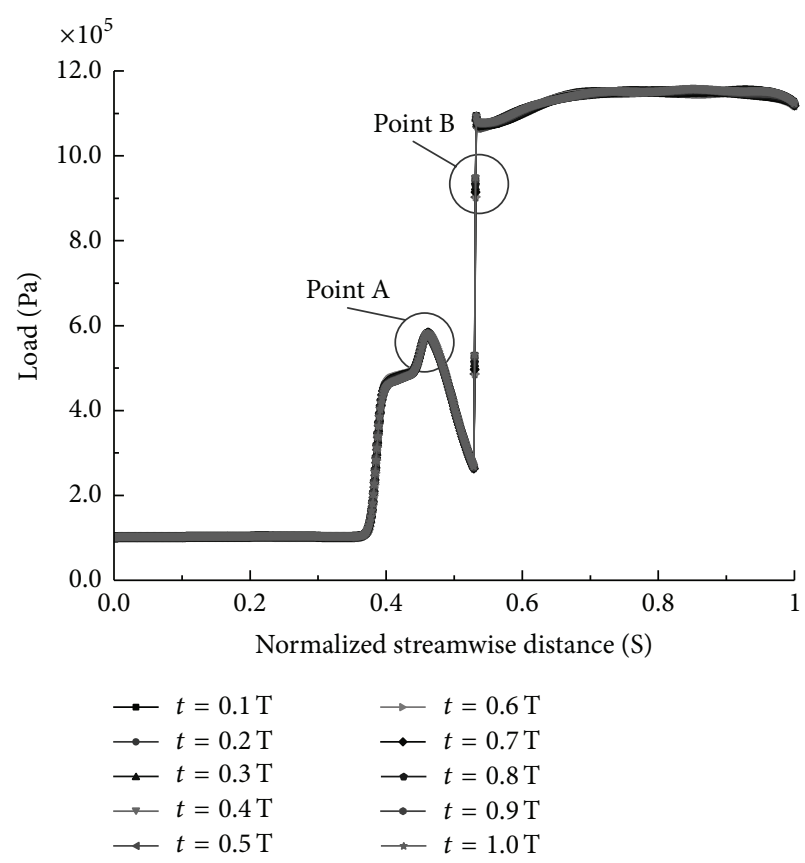

(a) Stationary engine case

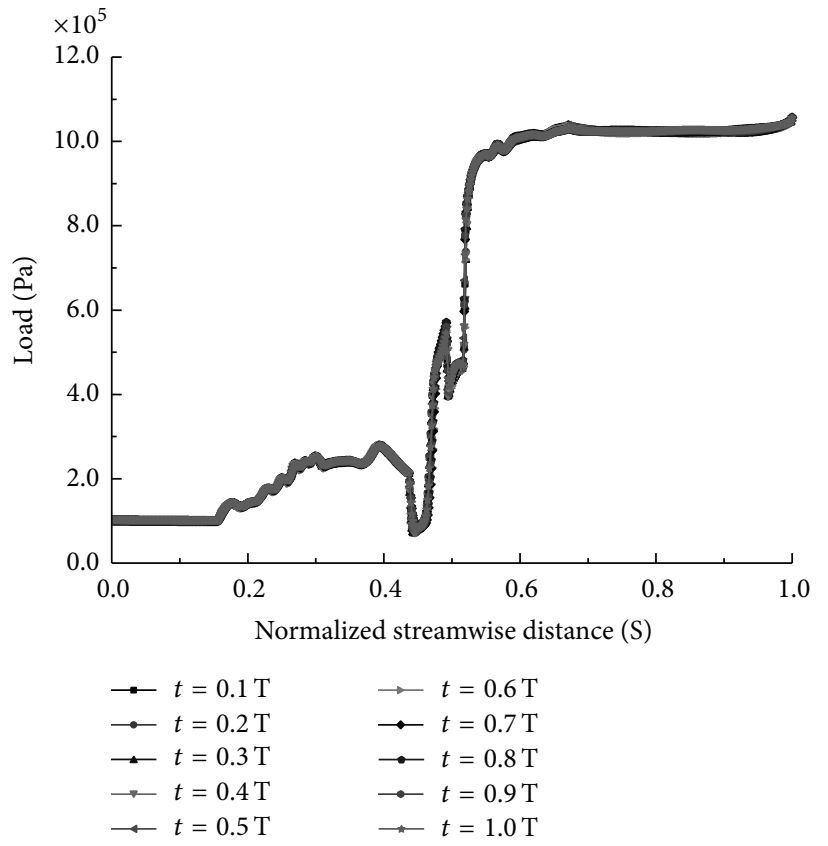

(b) Rotor rim surface

FIGURE 13: Pressure distributions along stationary engine case and rotor rim surface in a whirling motion cycle.

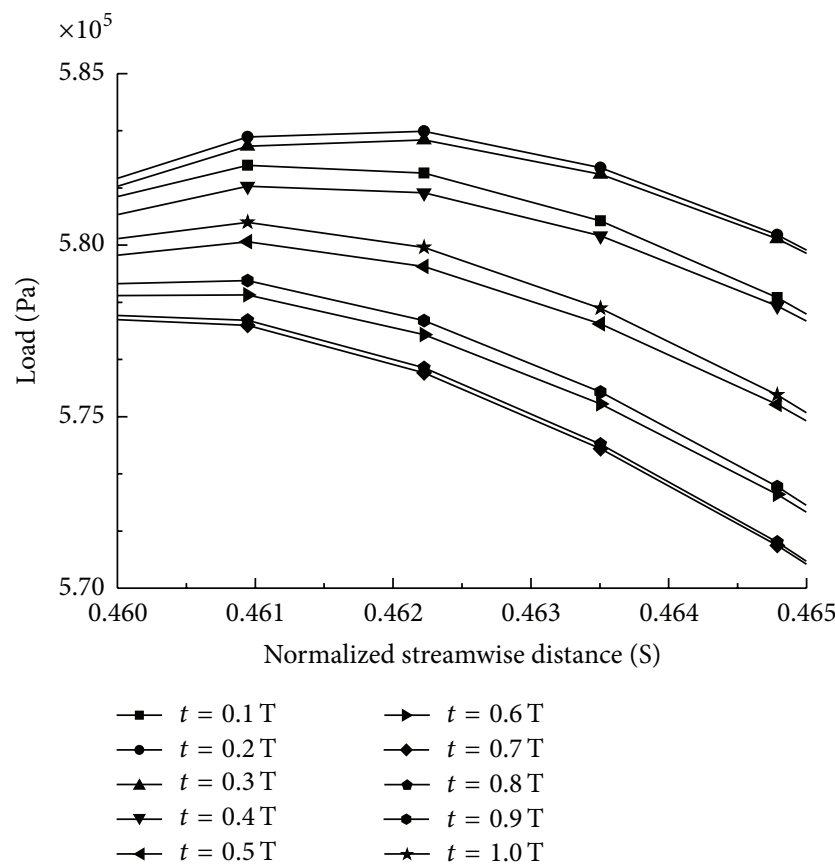

(a) Point A

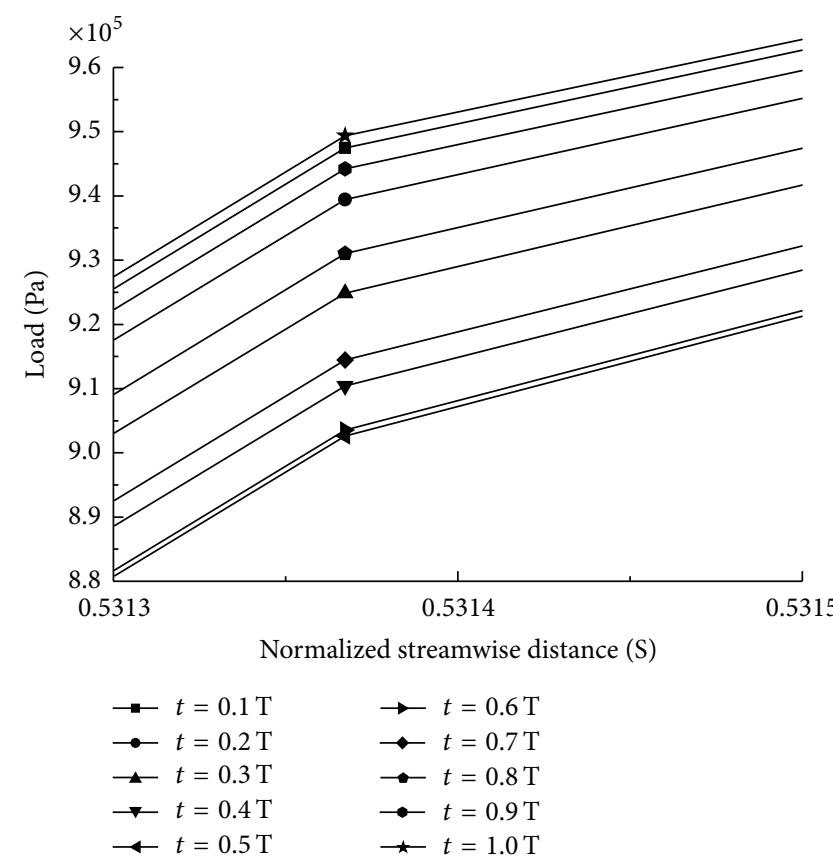

(b) Point B

FIgURE 14: Partial enlarged drawing of pressure distributions along stationary engine case.

The consequences of Rampressor inlet flow performance in different pressure ratios are shown in Table 1. With the increase of $P_{r}$ (back pressure), static pressure ratio $p_{s}$, total-pressure recovery coefficient $p_{R}$, pressurization ratio $p_{z}$, and kinetic energy efficiency $\eta$ gradually enhance, but nondimensional total pressure distortion and loss coefficient, decrease by degrees, and exit stability of Rampressor inlet ameliorates. As a result, appropriate enhancement of exit back pressure is advantageous to pressure ratio, compression efficiency, and other performance indices when inlet can 


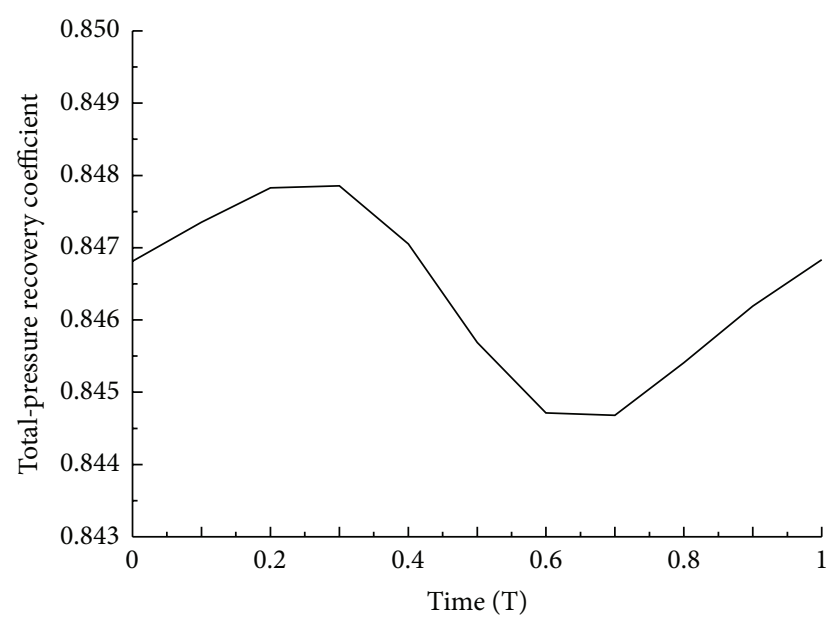

(a) Total-pressure recovery coefficient

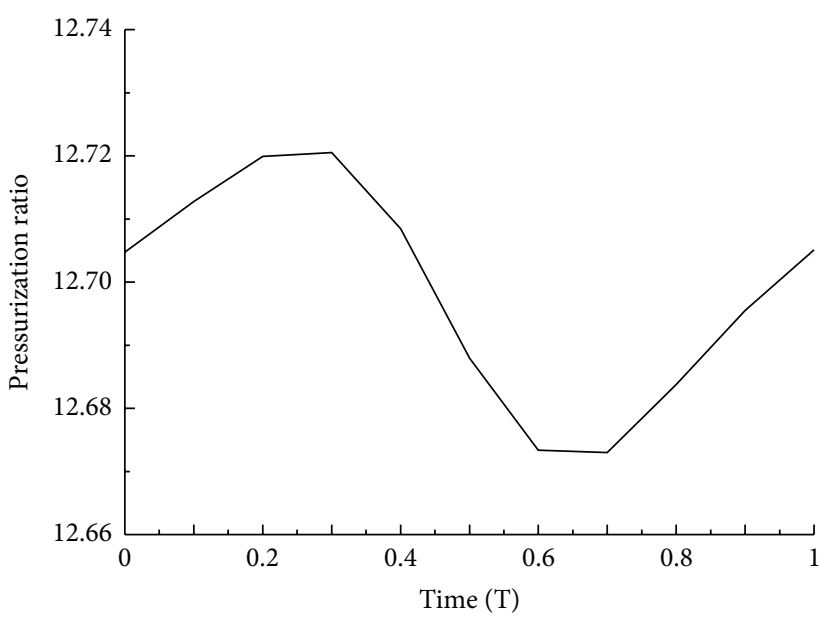

(b) Pressurization ratio

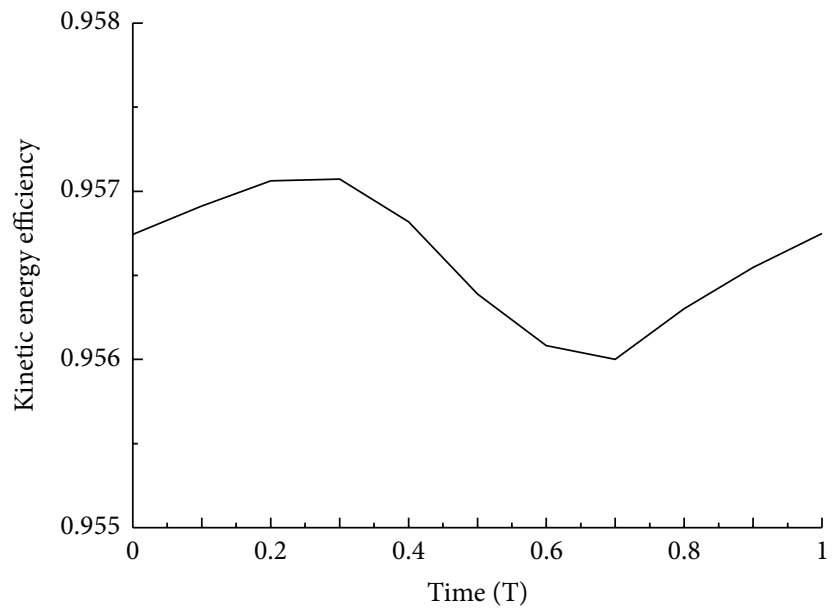

(c) Kinetic energy efficiency

FIGURE 15: Flow performance of Rampressor inlet in a whirling motion cycle.

TABLE 1: Flow performance parameters in the different $P_{r}$.

\begin{tabular}{lccccc}
\hline$p_{s}$ & $p_{R}$ & $p_{z}$ & $\bar{\omega}$ & $\eta$ & $\Delta(\%)$ \\
\hline 9 & 0.7649 & 11.48 & 0.0116 & 0.9292 & 36.73 \\
10 & 0.8294 & 12.44 & 0.0075 & 0.9512 & 43.39 \\
10.6 & 0.8483 & 12.73 & 0.0063 & 0.9572 & 25.46 \\
\hline
\end{tabular}

start and normally work and meanwhile beneficial to improvement of Rampressor overall efficiency.

4.2. Performance and Excitation Characteristic of Inlet under Rotor Whirling. Rampressor inlet flow may be affected by Rampressor rotor whirl in the work process. When the inlet pressure regularly changes, which is caused by rotor whirl, Rampressor rotor bears the inconstant pressure load and then vibrates.

Structure schematic diagram of inlet flow path under Rampressor rotor whirl is illustrated in Figure 10. The dotted line represents the state of Rampressor rotor without whirl, and the solid line curve represents the state of Rampressor rotor whirl.

Because the three inlets of the designed Rampressor are the symmetric periodic layout on the rotor, the flow excitation characteristics and flow performance of inlet flow path 1 are studied under Rampressor rotor periodic whirl in this paper. Expression of rotor periodic whirl is given as follows:

$$
e=a \sin (\Omega t+\varphi)
$$

where $e$ represents the displacement between Rampressor center $O^{\prime}$ under rotor whirl and Rampressor center $O$ without rotor whirl, $a$ is rotor whirl amplitude, $\Omega$ is rotor whirl frequency (whirl speed), and $\varphi$ is initial phase. In other words, the trajectory of the Rampressor rotor is assumed as a circle in different whirl frequencies and whirl amplitudes, so the effect of the damping on the rotor whirl is not taken into consideration in the calculation.

Result of steady flow is taken as the initial result in the unsteady calculation of this paper. Time step size is set to $1.478 \times 10^{-5} \mathrm{~s}$ in the design rotor speed. The unsteady flow of Rampressor inlet under rotor whirl is studied when $P_{r}$ equals 


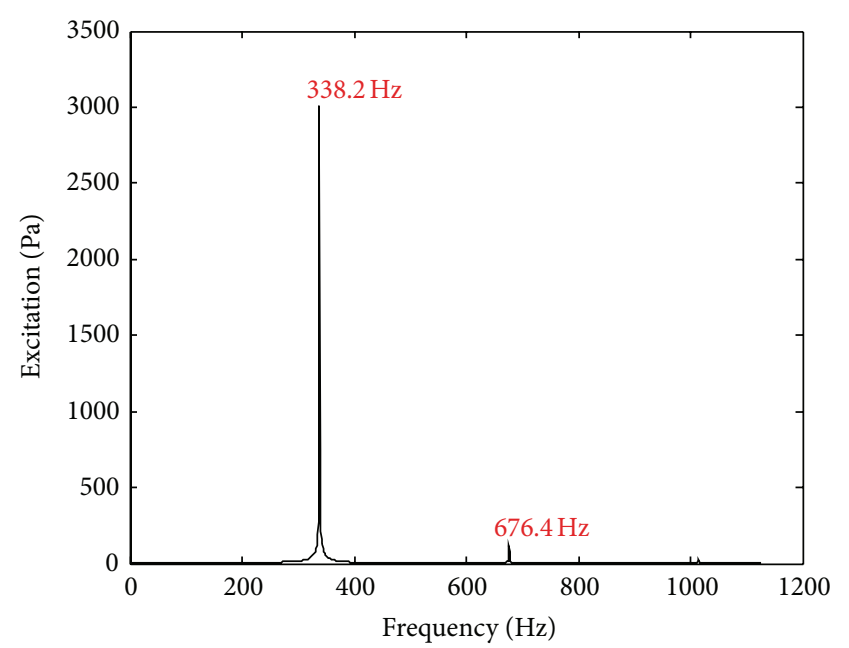

(a) $\Omega=2125 \mathrm{rad} / \mathrm{s}$

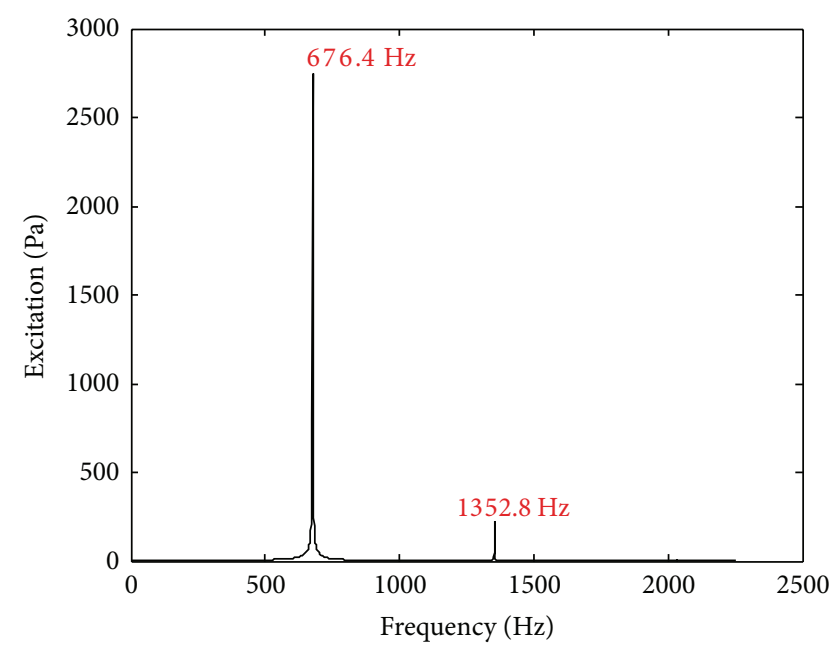

(b) $\Omega=4250 \mathrm{rad} / \mathrm{s}$

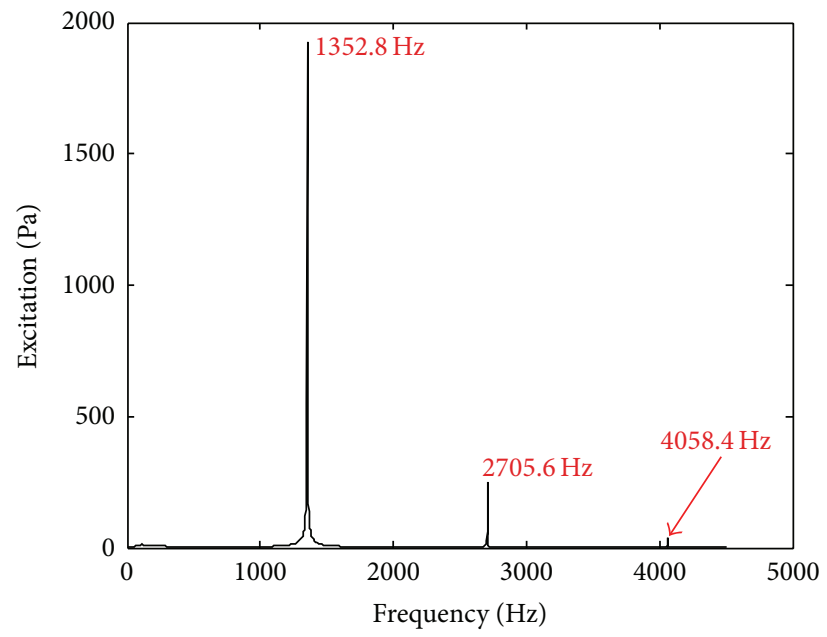

(c) $\Omega=8500 \mathrm{rad} / \mathrm{s}$

FIGURE 16: Calculation results of point D in different rotor whirling frequencies.

10.6. Flow excitation characteristics of Rampressor inlet will be analyzed under different frequencies and amplitudes of Rampressor whirl.

Pressure pulsation time history and spectrogram on every key point of Rampressor rotor inlet are shown in Figure 11 when rotor whirl amplitude equals $100 \mu \mathrm{m}$ and whirl speed $(\Omega)$ is $4250 \mathrm{rad} / \mathrm{s}$ (the design Rampressor rotor speed).

Figure 11 indicates that excitation spectrogram of point $\mathrm{A}$ located in inlet supersonic compression of Rampressor is relatively simple. The main frequency component is the fundamental frequency, which is caused by the rotor whirling. The value of rotor whirling frequency (fundamental frequency) is $676.4 \mathrm{~Hz}$, and excitation amplitude is small. Compared with point $\mathrm{A}$, more frequency components appear in the frequency spectrogram of Rampressor inlet point B, point $C$, and point $\mathrm{D}$. Not only rotor whirling frequency $676.4 \mathrm{~Hz}$ but also its double frequency component $1352.8 \mathrm{~Hz}$ is obtained in excitation spectrogram. The double frequency $1352.8 \mathrm{~Hz}$ is generated due to the coupling between inlet compression flow of Rampressor rotor and rotor whirling, especially in the subsonic diffuser of Rampressor rotor inlet. The amplitude of the double frequency component is smaller than that of the fundamental frequency component. As shown in the frequency spectrum, the excitation amplitudes of the fundamental frequency and double frequency components all gradually increase along with inlet flow path. This happens because the subsonic flow in Rampressor inlet is easily affected by the external excitation. It follows from above that the inlet excitation becomes more complex along with inlet flow path.

Time history of nondimensional excitation in a pulsation cycle is given (as shown in Figure 12) on every key point of Rampressor rotor inlet when rotor whirl amplitude equals $100 \mu \mathrm{m}$ and whirl speed $(\Omega)$ is $4250 \mathrm{rad} / \mathrm{s}$. Figure 12 shows that phases of nondimensional excitation in different measure points are greatly different. Among them, phase difference between point $\mathrm{B}$ located on the entrance of the inlet throat and point $C$ located on exit of the inlet throat is close to 180 degrees. Thus it can be seen that rotor whirl effect on inlet different location excitation has a certain phase difference. 


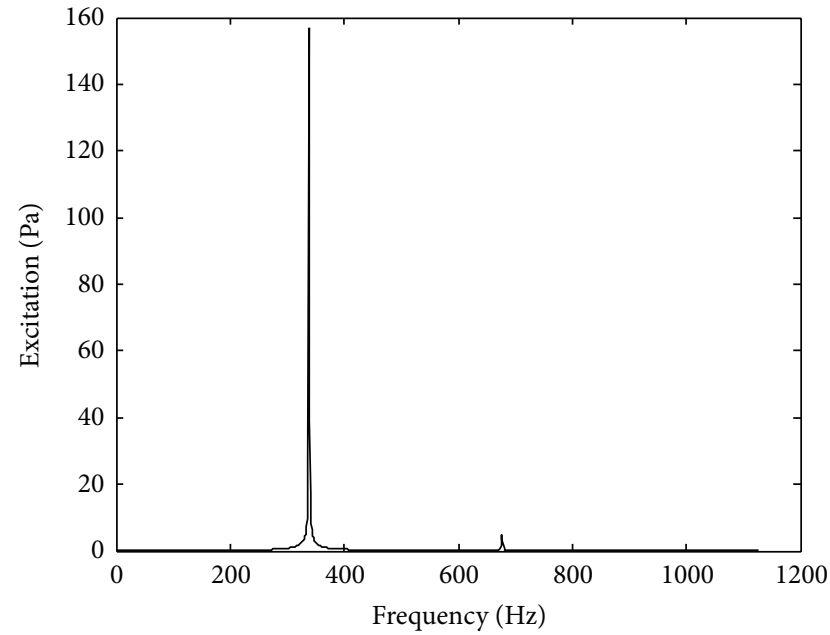

(a) $\Omega=2125 \mathrm{rad} / \mathrm{s}$

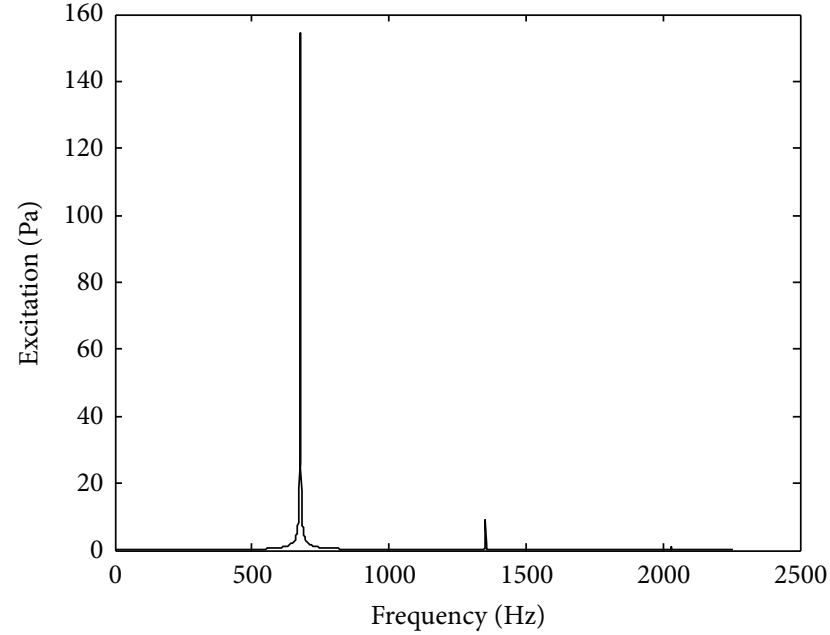

(b) $\Omega=4250 \mathrm{rad} / \mathrm{s}$

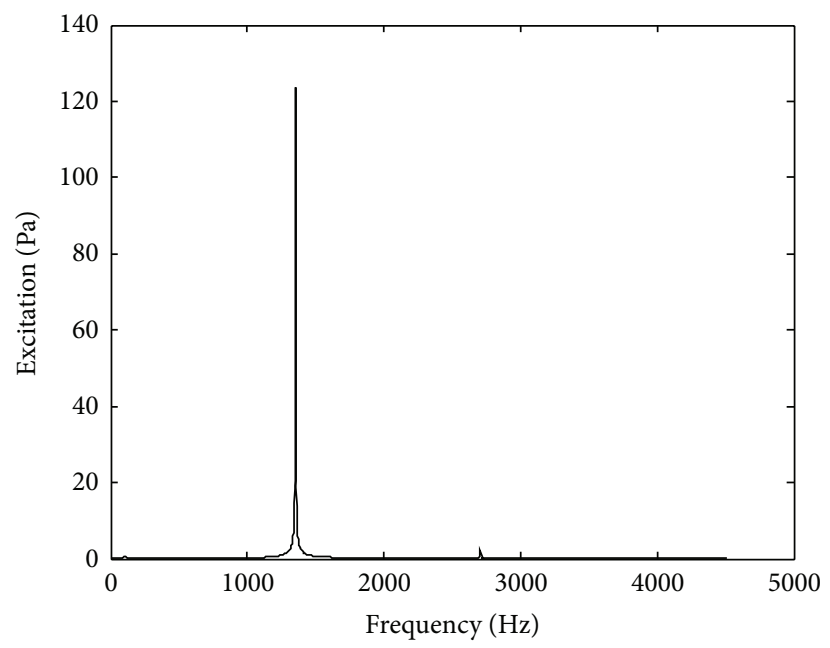

(c) $\Omega=8500 \mathrm{rad} / \mathrm{s}$

FIGURE 17: Calculation results of airflow exciting force on the rotor rim surface of Rampressor inlet in different rotor whirling frequencies.

Pressure distributions along stationary engine case and rotor rim surface of Rampressor inlet in a whirling motion cycle are shown in Figure 13 when rotor whirl amplitude equals $100 \mu \mathrm{m}$ and whirl speed $(\Omega)$ is $4250 \mathrm{rad} / \mathrm{s}$.

Figure 14 shows partial enlarged drawing of pressure distributions along the stationary engine case of Rampressor inlet (as shown in Figure 13(a); point A and point B). Periodic oscillation phenomenon of the inlet pressure distribution is obtained under Rampressor rotor whirl.

The curves of flow performance parameters of Rampressor inlet in a whirling motion cycle are shown in Figure 15 when rotor whirl amplitude equals $100 \mu \mathrm{m}$ and whirl speed $(\Omega)$ is $4250 \mathrm{rad} / \mathrm{s}$. Figure 15 indicates that the variations of total-pressure recovery coefficient, pressure ratio, and kinetic energy efficiency for Rampressor inlet are also periodic in a whirling motion cycle.

4.2.1. Results and Discussion in Different Frequencies of Rampressor Rotor Whirl. Pressure pulsation spectrograms of key point D (shown in Figure 6) are, respectively, obtained in different whirling frequencies such as $\Omega=2125 \mathrm{rad} / \mathrm{s}$, $4250 \mathrm{rad} / \mathrm{s}$, and $8500 \mathrm{rad} / \mathrm{s}$ (shown in Figure 16) when rotor whirl amplitude is $100 \mu \mathrm{m}$.

Figure 17 shows the spectrograms of airflow exciting force on Rampressor rotor rim surface when rotor whirling amplitude equals $100 \mu \mathrm{m}$ and rotor whirl frequencies are $2125 \mathrm{rad} / \mathrm{s}, 4250 \mathrm{rad} / \mathrm{s}$, and $8500 \mathrm{rad} / \mathrm{s}$, respectively.

Figure 16 indicates that the excitation characteristic of point $\mathrm{D}$ is rather complex. As shown in the frequency spectrum, besides the fundamental frequency component, the higher order frequency component is also generated, where the amplitude of the fundamental frequency component is the highest. The amplitude of the double frequency component is smaller than that of the fundamental frequency, but greater than those of other frequency components. Compared with excitation spectrum of $\Omega=2125 \mathrm{rad} / \mathrm{s}$, the amplitude of the double frequency component relatively increses when the whirl frequency $(\Omega)$ is $4250 \mathrm{rad} / \mathrm{s}$ 


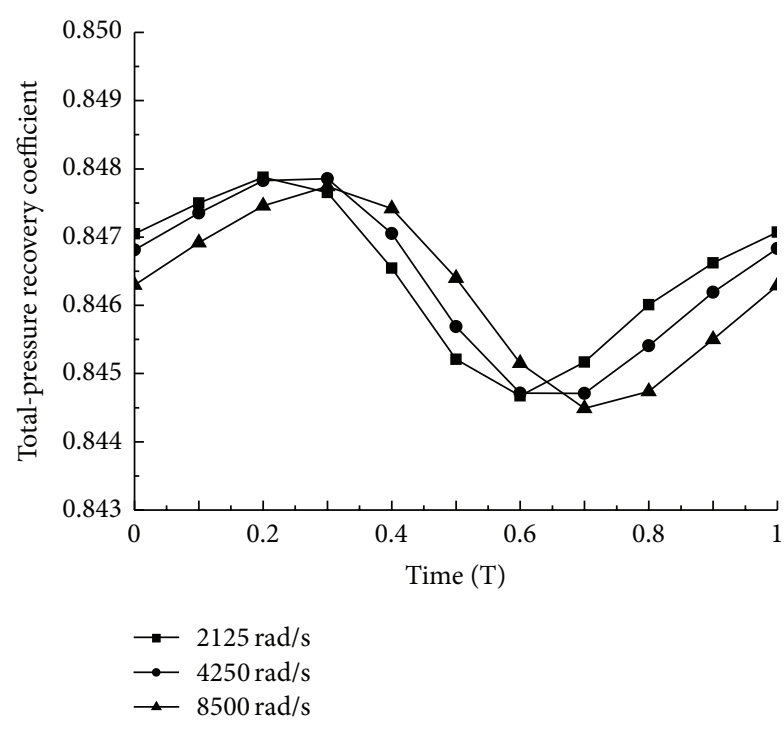

(a) Total-pressure recovery coefficient

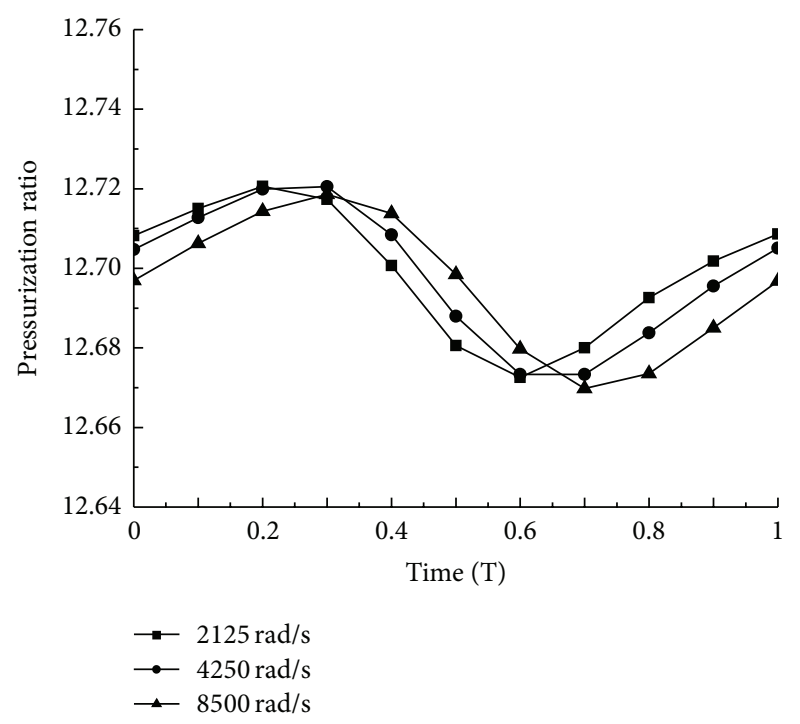

(b) Pressurization ratio

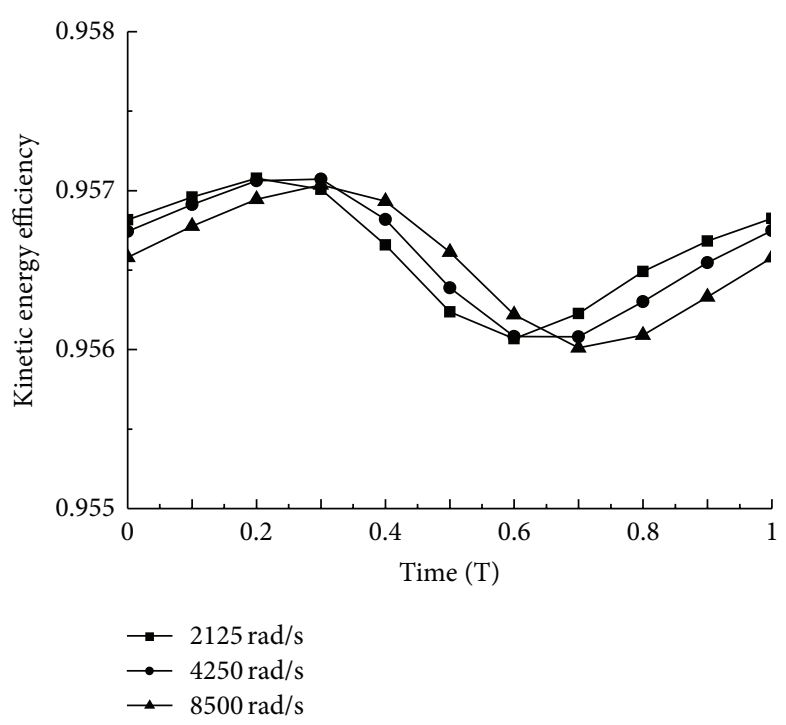

(c) Kinetic energy efficiency

FIGURE 18: Flow performance in different whirling frequencies during a whirling motion cycle.

(as shown in Figure 16(b)). In Figure 16(c), more frequency components appear in the excitation spectrum. In addition to the fundamental frequency and double frequency component, the third harmonic frequency component simultaneously emerges when the whirl frequency $(\Omega)$ is $8500 \mathrm{rad} / \mathrm{s}$, which is caused by the coupling between inlet compression flow of Rampressor rotor and rotor whirling. With the increment of rotor whirling frequency, the amplitude of the fundamental frequency component in the frequency spectrum gradually decreases, but the amplitude of the double frequency component increases by degrees. It follows from above that the complexity of Rampressor inlet excitation increases along with the increase of rotor whirling frequency. The above results are also illustrated in the frequency spectrum of airflow exciting force on the rotor rim surface of Rampressor inlet as shown in Figure 17.

The curves of flow performance parameters of Rampressor inlet in a whirling motion cycle are, respectively, obtained in different whirl frequencies such as $\Omega=2125 \mathrm{rad} / \mathrm{s}$, $4250 \mathrm{rad} / \mathrm{s}$, and $8500 \mathrm{rad} / \mathrm{s}$ (illustrated in Figure 18) when rotor whirl amplitude is $100 \mu \mathrm{m}$. Figure 18 shows that wave amplitudes of total-pressure recovery coefficient, pressurization ratio, and kinetic energy efficiency of Rampressor inlet are not affected by rotor whirling frequency, which only influences the wave frequency of inlet flow performance parameters. The wave frequency of inlet flow performance parameters becomes higher with the increment of rotor whirl frequency. Therefore, the stability of inlet performance is 


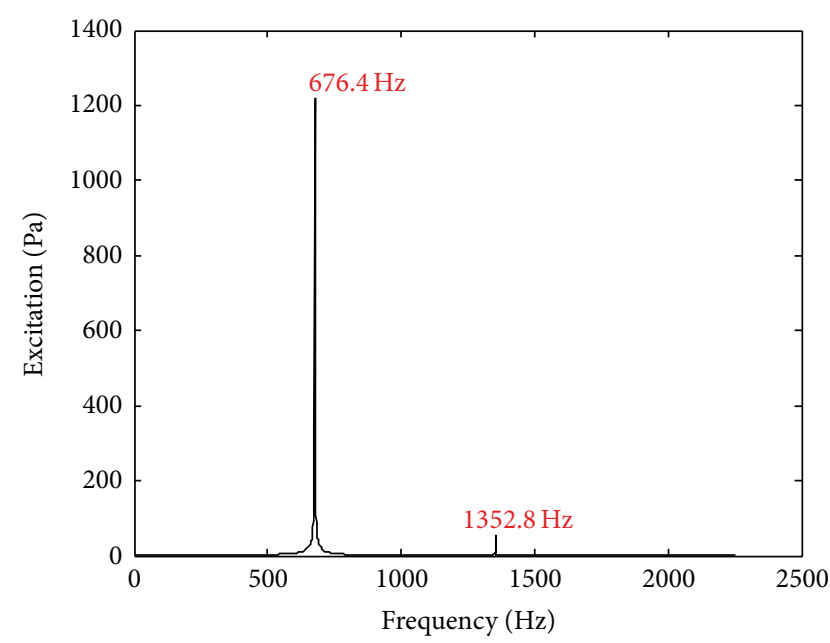

(a) $a=50 \mu \mathrm{m}$

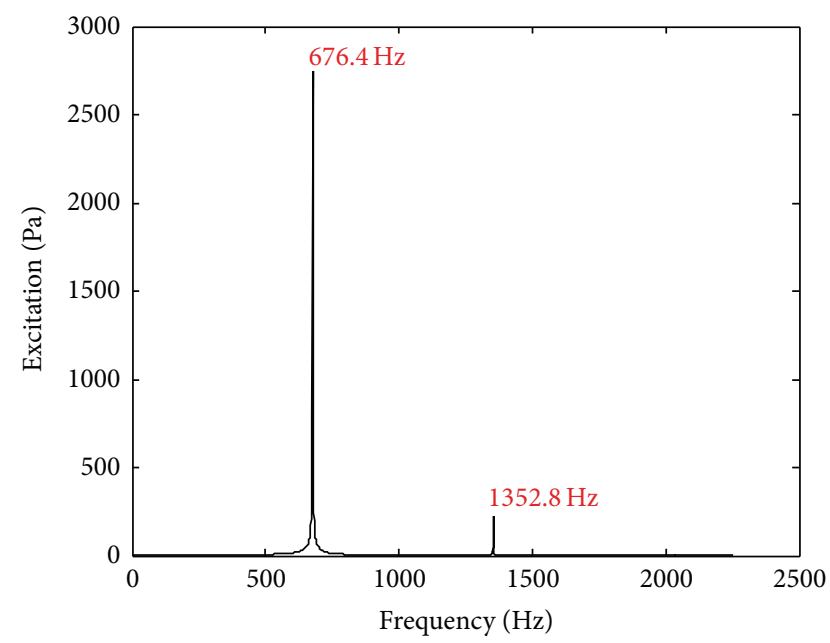

(b) $a=100 \mu \mathrm{m}$

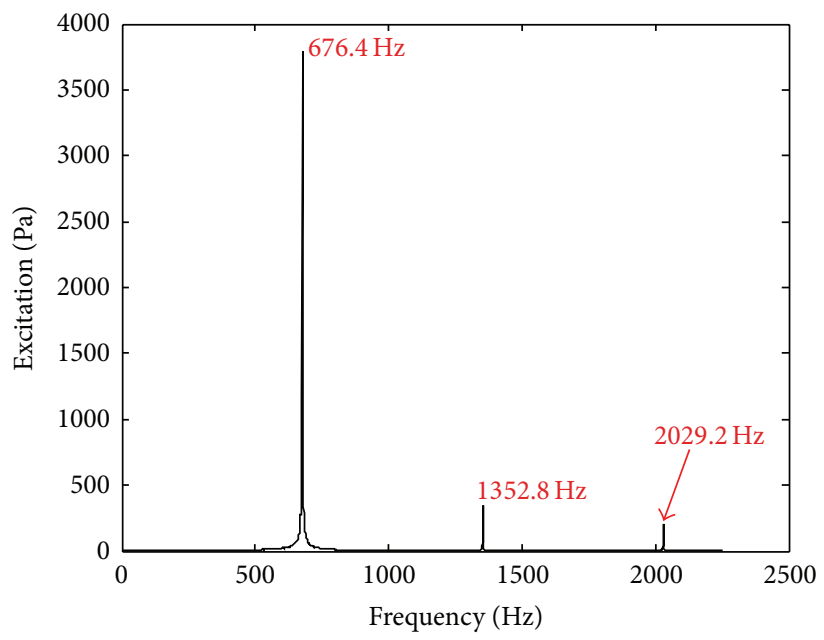

(c) $a=150 \mu \mathrm{m}$

FIGURE 19: Calculation results of point $\mathrm{D}$ in different rotor whirling amplitudes.

better in the practical engineering when Rampressor rotor whirling frequency is less.

4.2.2. Results and Discussion in Different Amplitudes of Rampressor Rotor Whirl. Excitation characteristics of Rampressor inlet are analyzed in different rotor whirling amplitudes such as $a=50 \mu \mathrm{m}, a=100 \mu \mathrm{m}$, and $a=150 \mu \mathrm{m}$ when rotor whirling frequency $\Omega=4250 \mathrm{rad} / \mathrm{s}$. Figure 19 shows pressure pulsation spectrogram of Rampressor inlet key point D (shown in Figure 6) in different rotor whirl amplitudes.

The spectrograms of airflow exciting force on Rampressor rotor rim surface are, respectively, obtained in different rotor whirling amplitudes such as $a=50 \mu \mathrm{m}, a=100 \mu \mathrm{m}$, and $a=$ $150 \mu \mathrm{m}$ (shown in Figure 20) when the rotor whirl frequency $\Omega=4250 \mathrm{rad} / \mathrm{s}$.

As shown in Figure 19, more frequency components emerge in the excitation spectrum such as the fundamental frequency component, double frequency component, and third harmonic frequency component, where the amplitude of the fundamental frequency component is the highest. The amplitude of the double frequency component is smaller than that of the fundamental frequency component, but higher than that of the third harmonic frequency component. Compared with point D excitation of $a=50 \mu \mathrm{m}$, besides the fundamental frequency and double frequency components, the third harmonic component in excitation spectrum is also generated when the rotor whirl amplitudes are $100 \mu \mathrm{m}$ and $150 \mu \mathrm{m}$ (as shown in Figures 19(b) and 19(c)), and the amplitude of the double frequency component in the excitation spectrum of inlet point $\mathrm{D}$ relatively increases. With the increment of rotor whirling amplitude, the amplitude of the fundamental frequency component and double frequency component in the excitation spectrum of inlet wall all gradually increases. It follows from above that the complexity of Rampressor inlet excitation also increases along with the increase of rotor whirling amplitude. The above results are also illustrated in the spectrum of airflow exciting force on the rotor rim surface of Rampressor inlet as shown in Figure 20. 


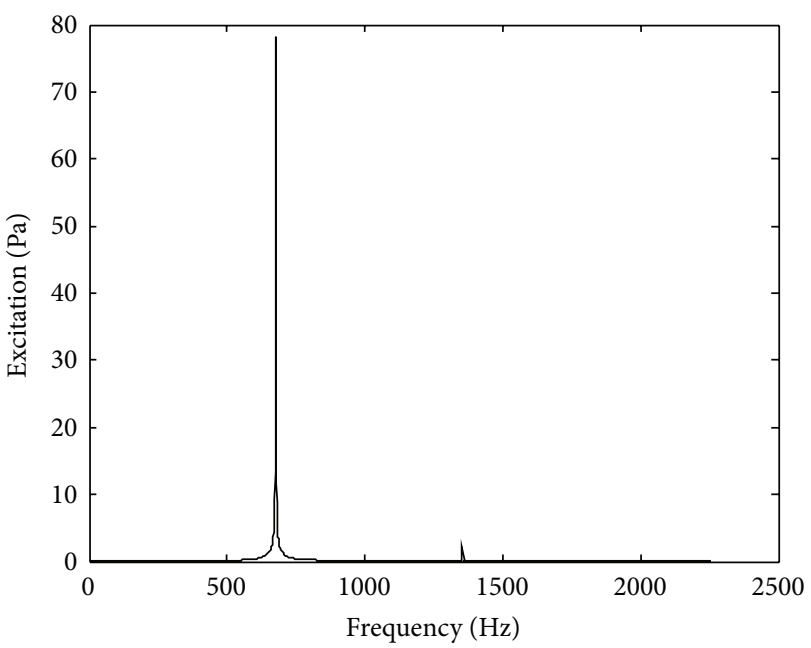

(a) $a=50 \mu \mathrm{m}$

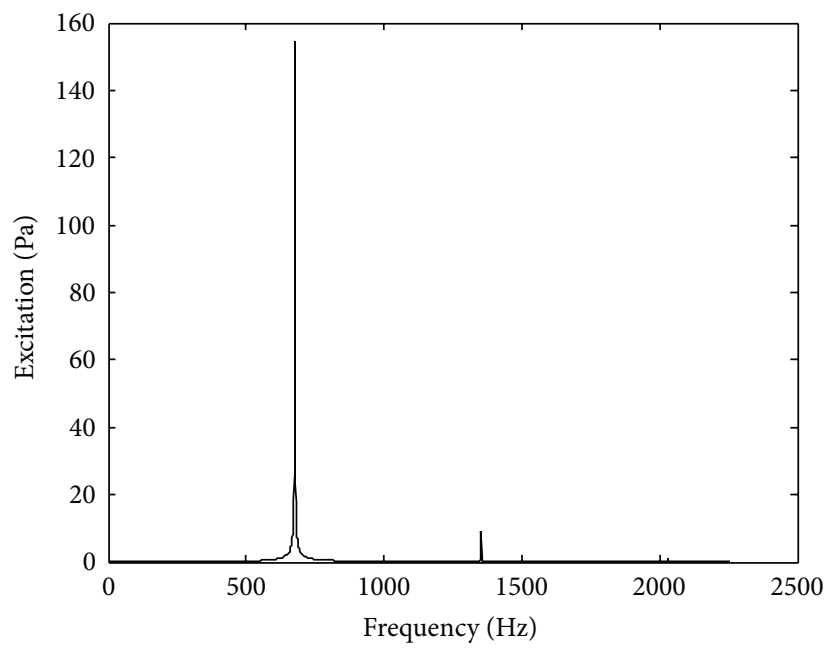

(b) $a=100 \mu \mathrm{m}$

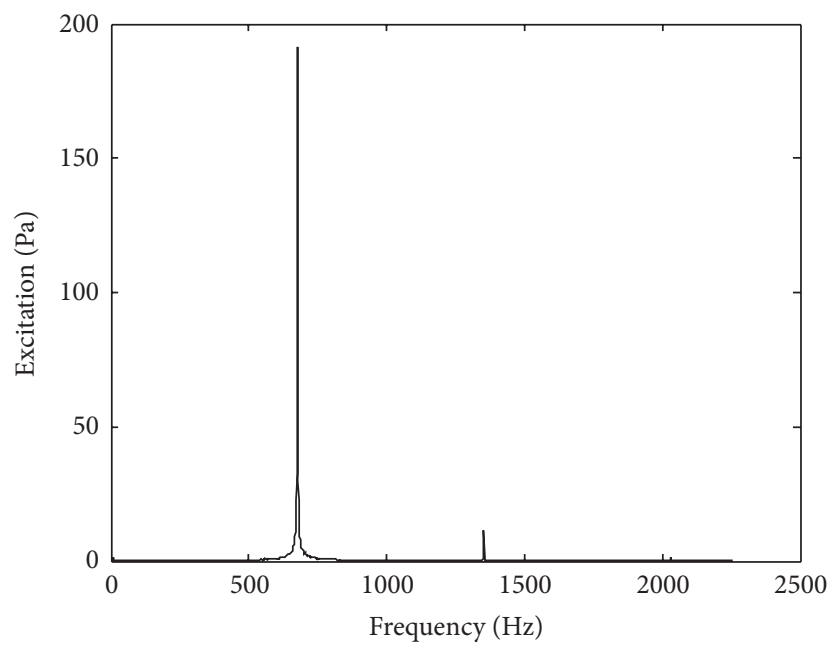

(c) $a=150 \mu \mathrm{m}$

FIGURE 20: Calculation results of airflow exciting force on the rotor rim surface of Rampressor inlet in different rotor whirling amplitudes.

Flow performance of Rampressor inlet is studied in different rotor whirling amplitudes such as $a=50 \mu \mathrm{m}, a=$ $100 \mu \mathrm{m}$, and $a=150 \mu \mathrm{m}$ when rotor whirling frequency $\Omega=$ $4250 \mathrm{rad} / \mathrm{s}$. Figure 21 shows the curves of flow performance parameters of Rampressor inlet during a whirling motion cycle in different rotor whirling amplitudes. Along with the increase of rotor whirling amplitude, wave amplitudes of total-pressure recovery coefficient, pressurization ratio, and kinetic energy efficiency of Rampressor inlet enlarge, and the stability of inlet performance reduces. Therefore, the stability of inlet performance is better in the practical engineering when Rampressor rotor whirling amplitude is less.

\section{Conclusions}

Based on Rampressor rotor model and inlet flow model, the compression inlet flow field of Rampressor rotor is numerically studied with consideration of Rampressor rotor whirling. Flow excitation characteristics and performance of Rampressor inlet are analyzed and discussed under the different frequencies and amplitudes of Rampressor rotor whirling. The following conclusions are obtained.

Along with the increment of $P_{r}$, the position of the normal shock wave gradually moves forward, and aerodynamic loading of the inlet wall also increases. Appropriate enhancement of inlet back pressure is advantageous to the pressure ratio, compression efficiency, and other performance indices when inlet can start and normally work.

More frequency components appear in the excitation spectrum of Rampressor inlet with considering Rampressor rotor whirling. The main frequency component is the fundamental frequency, which is caused by the rotor whirling. Besides the fundamental frequency, the double frequency components emerge because of the coupling between inlet compression flow of Rampressor rotor and rotor whirling, especially in the subsonic diffuser of Rampressor rotor inlet. The effect of rotor whirling on the excitation of Rampressor inlet wall has a definite phase difference. Inlet excitation 


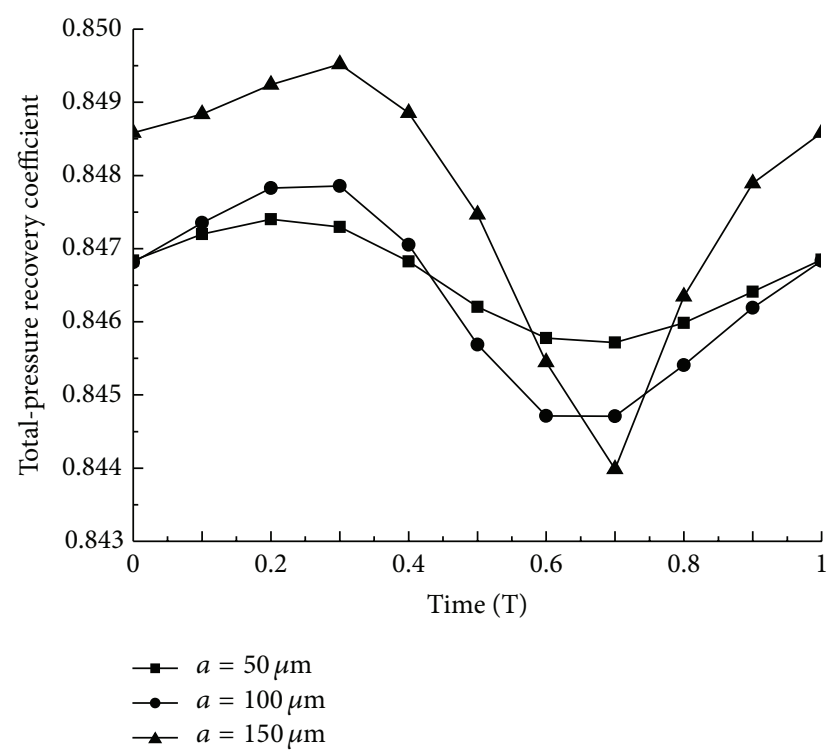

(a) Total-pressure recovery coefficient

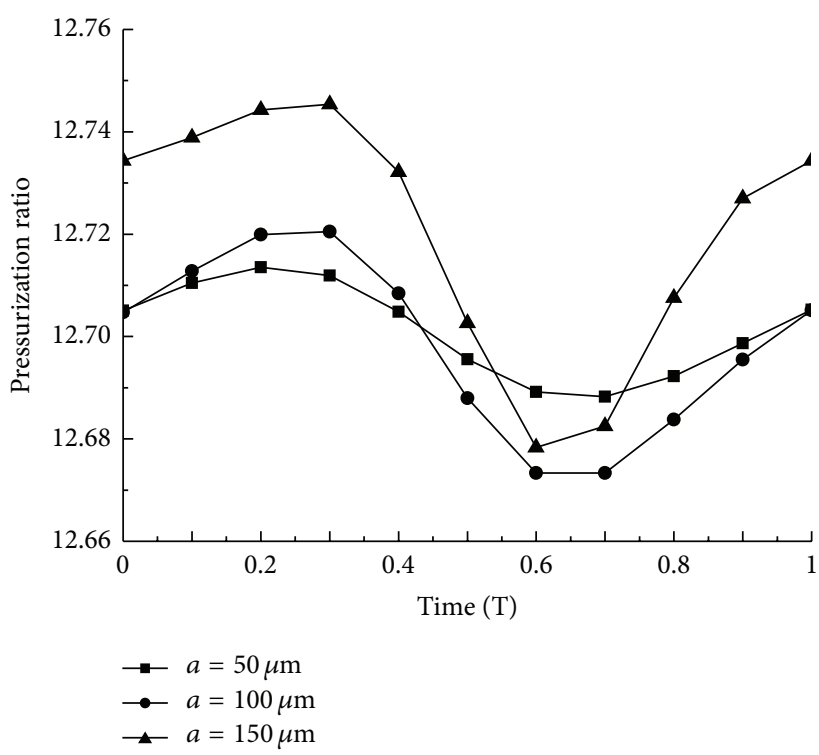

(b) Pressurization ratio

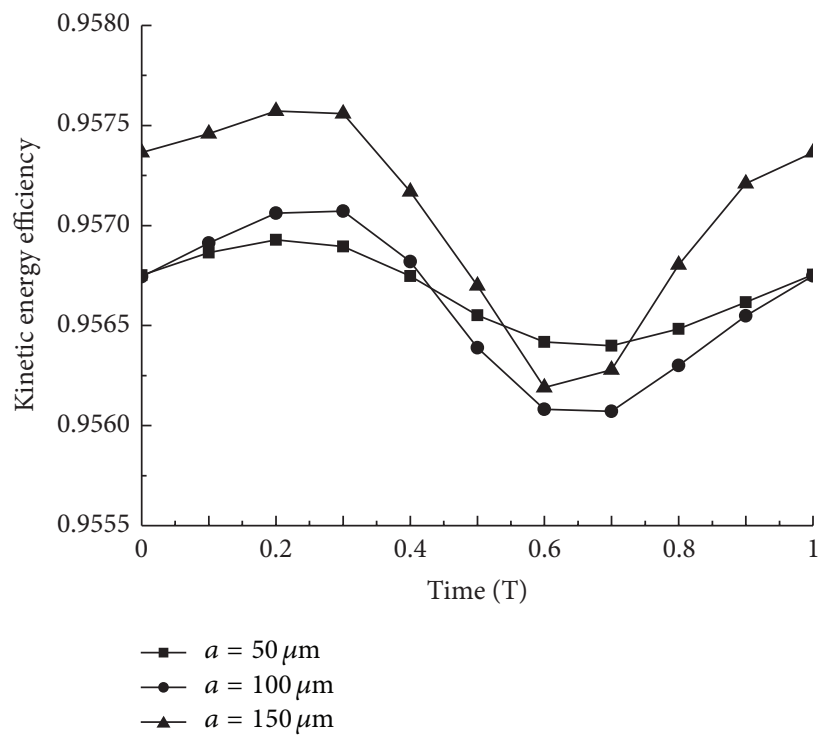

(c) Kinetic energy efficiency

FIGURE 21: Flow performance in different rotor whirling amplitudes during a whirling motion cycle.

becomes more complex along with inlet flow path. With the increase of rotor whirling frequency and whirling amplitude, the complexity of Rampressor inlet excitation increases.

With the increase of rotor whirling amplitude, wave amplitudes of total-pressure recovery coefficient, pressurization ratio, and kinetic energy efficiency of Rampressor inlet gradually enlarge, and the stability of inlet performance reduces. But wave amplitudes of total-pressure recovery coefficient, pressurization ratio and kinetic energy efficiency of Rampressor inlet are constant with the increment of rotor whirling frequency, and only wave frequency of inlet flow performance parameters increases. Stability of inlet performance is better in the practical engineering when
Rampressor rotor whirling frequency and amplitude are all less.

\section{Conflict of Interests}

The authors declare that there is no conflict of interests regarding the publication of this paper.

\section{Acknowledgments}

The research presented here was supported by the National Natural Science Foundation of China (Grant no. 51106035). 
The authors are grateful for the support provided. The authors would like to thank Dr. Guanghui Zhang and M.S. Jianhua Lu for their constructive suggestions and/or assistant provided.

\section{References}

[1] S. P. Lawlor, B. J. Hinkey, and S. G. Mackin, "Supersonic compressor stage design \& test results," IMECE2004-59914, 2004.

[2] R. Draper and R. Steele, Design of Diffuser for High Mach and High Swirl Applications[EB/OL], 2003, http://www.clemson .edu/scies/UTSRPeerReview/Proceeding20content/Poster20session/Poster Draper.pdf.

[3] Ramgen Power Systems Inc, "Ramgen engine technology overview briefing [EB/OL]," March 2002, http://www.netl.doe .gov/publications/proceedings/02/turbines/steele.pdf.

[4] R. Steele, P. Baldwin, and J. Kesseli, "Insertion of shock wave comp ression technology into micro turbines for increased efficiency and reduced costs," ASME Paper GT2005-68203, 2008.

[5] A. D. Grosvenor, D. A. Taylor, and J. R. Bucher, "Measured and predicted performance of a high pressure ratio supersonic compressor rotor," ASME Paper GT2008-50150, 2008.

[6] A. D. Grosvenor, P. M. Brown, and S. P. Lawlor, "Design Methodology and Predicted Performance for a Supersonic Compressor Stage," ASME Paper GT2006-90409, 2006.

[7] J. A. Han, H. M. Yan, J. J. Zhong, P. Sun, and Y. Yu, "Numerical research of two-dimensional flow-path in ram-rotor," Journal of Aerospace Power, vol. 23, no. 6, pp. 1054-1060, 2008.

[8] J. A. Han, J. J. Zhong, H. M. Yan, P. Sun, and Y. Yu, "Numerical research of three dimensional flow-path in a ram-rotor," Journal of Aerospace Power, vol. 24, no. 5, pp. 1079-1088, 2009.

[9] L. Yang, J. J. Zhong, and J. A. Han, "Numerical research of the ram-rotor with different geometric parameters," ASME Paper GT2011-46051, 2011.

[10] S. P. Lawlor and P. Baldwin, "Conceptual design of a supersonic $\mathrm{CO}_{2}$ compressor,” ASME Paper GT2005-68349, 2005.

[11] Ramgen Power Systems Inc, Gas Turbine Engine: Shock Wave Based Ramgen Engine, http://www.ramgen.com/apps_ASCE_ breakthrough.htm. 

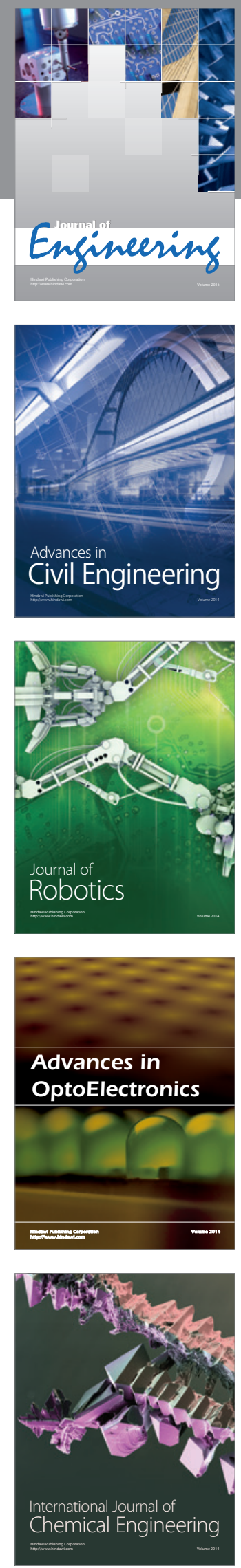

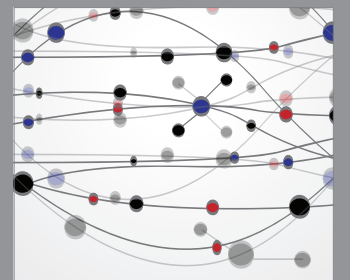

The Scientific World Journal
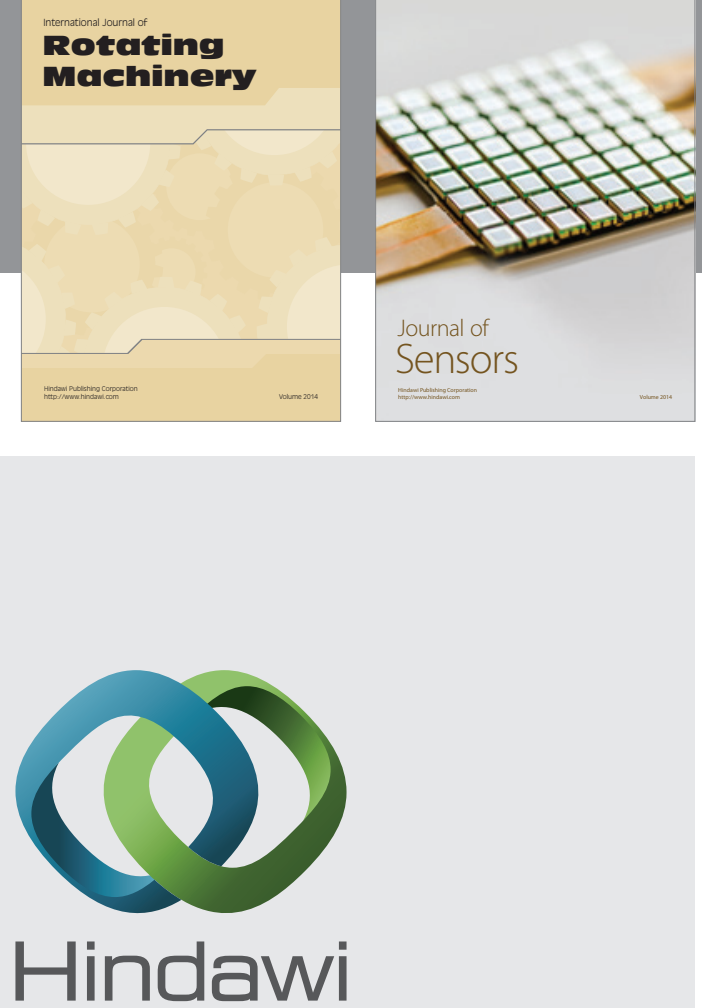

Submit your manuscripts at http://www.hindawi.com
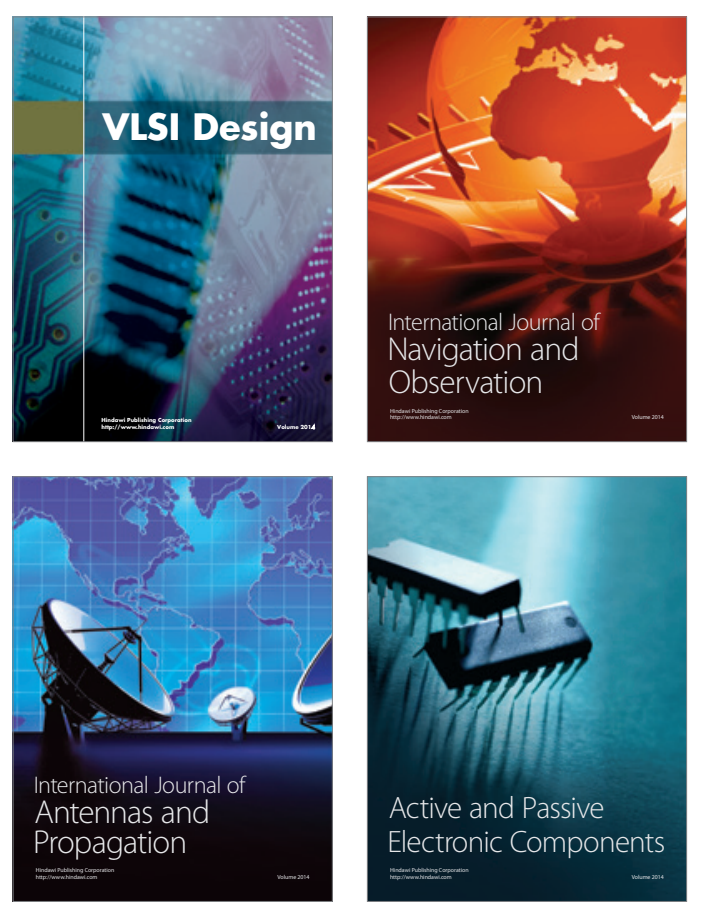
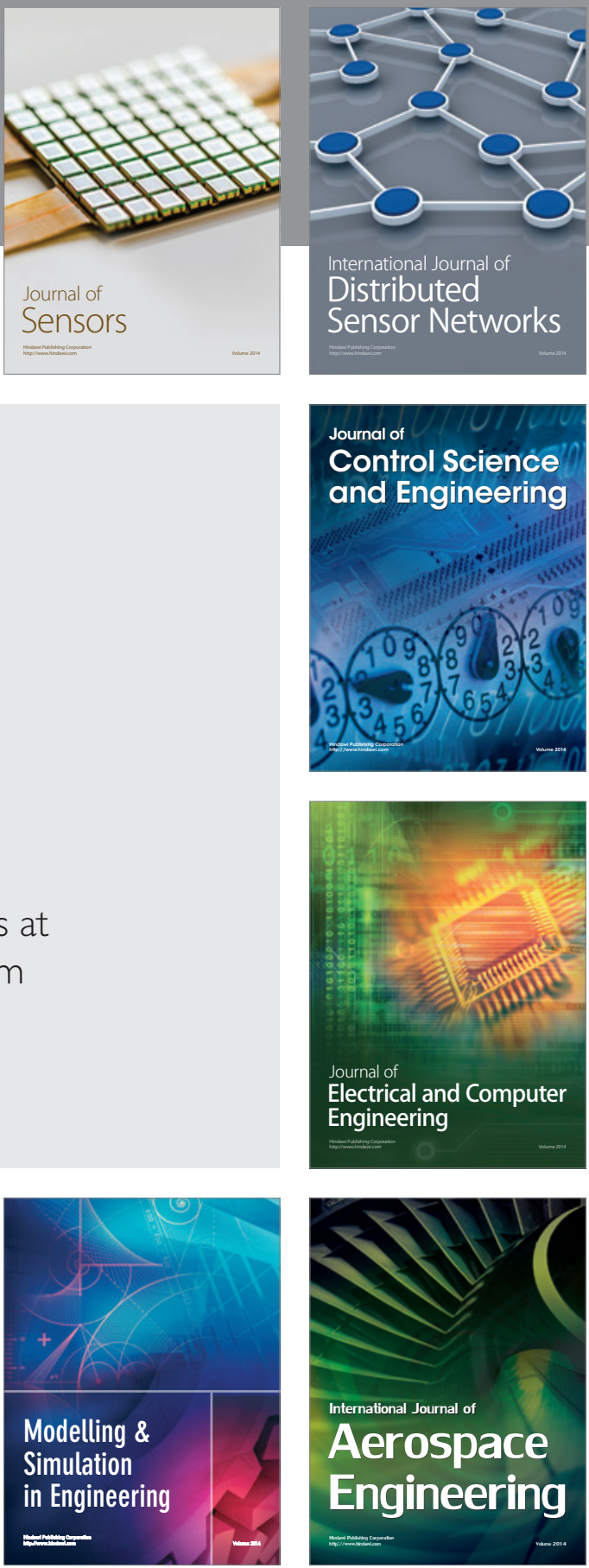

Journal of

Control Science

and Engineering
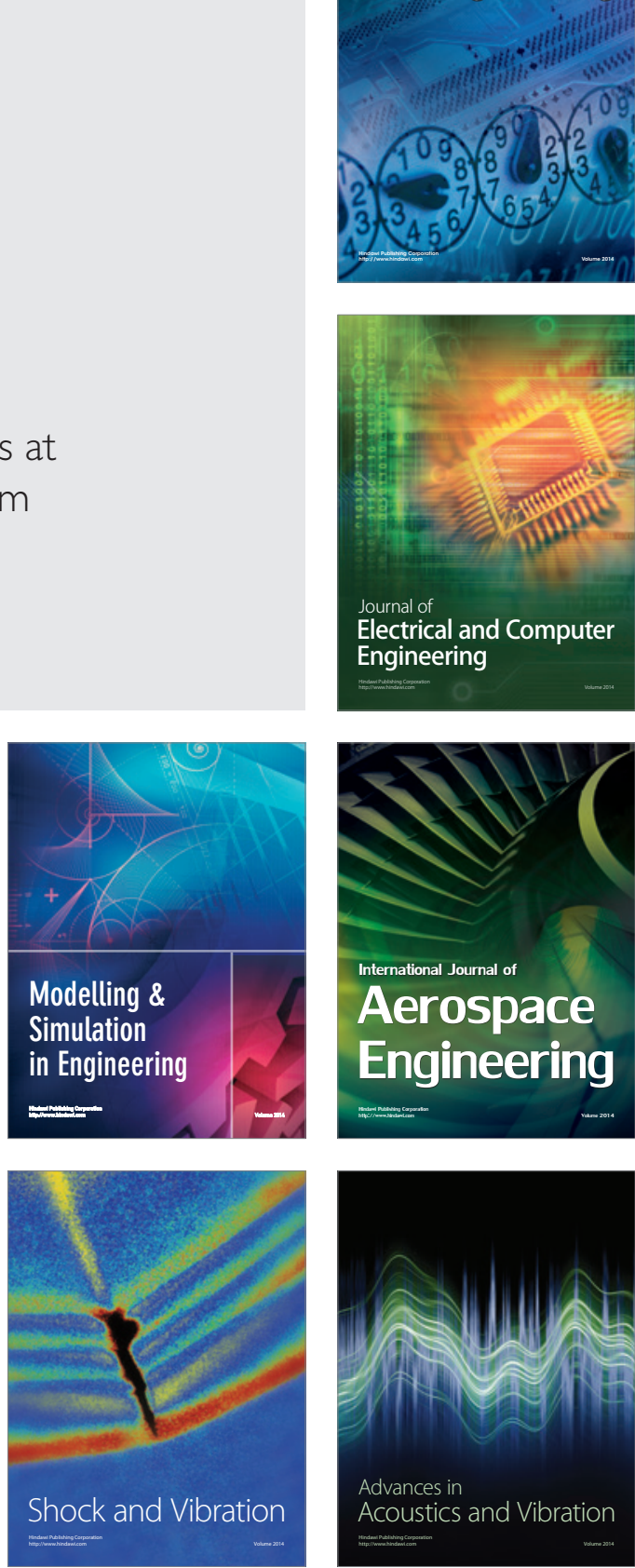